\title{
Narratives of Indian Parents of Children Diagnosed with Autism Spectrum Disorder
}

\section{Yashaswini Gupta}

\author{
Supervised by: \\ Professor Anita Ghai
}

School of Human Studies

Ambedkar University Delhi

Kashmere Gate,

New Delhi

2020

अम्बेडकर विश्वविद्यालय दिल्ली

Ambedkar University Delhi 


\section{Acknowledgements}

Foremost, I would like to express my sincere gratitude to my supervisor Professor Anita Ghai for the continuous support during my Master's study and research, for her patience, motivation, and guidance. Her guidance helped me in all the time of research, from conception, selecting participants, to the writing of the dissertation.

I would also like to acknowledge the support of School of Human Studies, Ambedkar University Delhi, and their continued diligence and logistical support throughout the duration of this research.

This research could not have been possible without its participants, and I extend my gratitude for agreeing to share their valuable time with me. Additionally, I would like to thank Forum for Autism, 'Autism India' Facebook support group, Kamayani ma'am, Pranay Singh, Prakriti Pandiya and Srishti for helping me reach out to these participants and formulate the interview process.

My sincerest thanks to my peers and classmates, including Ishita Goyal, Sanchi Sharma, Akanksha Gupta, Ankur Sharma, Amishaa Gupta and Manvi for their emotional support as well as their valued contribution to the dissertation through researches, journal articles, transcribing and feedback.

Lastly, I would like to thank my parents and my family for their continued love and motivation through my life, and for providing me with the capability of carrying out this research. No endeavour would be possible without their support. 


\section{Contents}

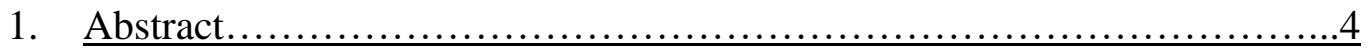

2. Introduction..................................................

3. Literature Review.............................................. 12

4. Ontology, Epistemology and Methodology ..........................22

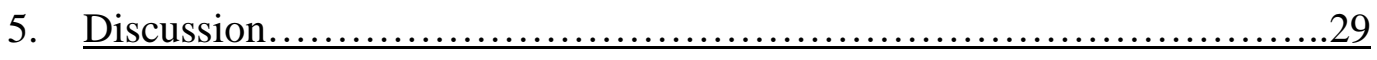

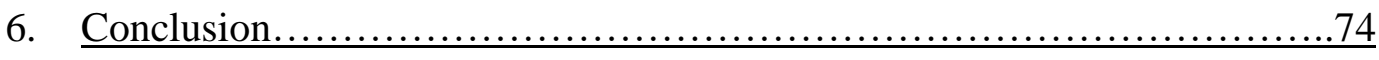

7. References........................................................ 78

8. $\quad$ Appendix A.................................................... 84

9. Appendix B.................................................. 87 


\begin{abstract}
Autism has been a widely studied psychological phenomenon. However, the importance of the role of parents as caregivers in the life of the child with autism has not researched much in the Indian context. Parents of children with autism were asked to participate through Facebook support groups and Forum for Autism (India), and phone interviews were help with six parents (three mothers and three fathers) belonging to different parts of India. Using the Narrative Thematic Analysis technique, themes were drawn out from the content and delivery of the narratives. The themes that emerged from the analysis were 'Lack of Knowledge about Autism', 'Emotional Upheaval of Parents', 'Role of Mothering', 'Role of Fathering', 'Childcentric Lifestyles', 'Presence of Social Support' and 'Effects of Sociocultural and Economic Positioning of the parents'. They were viewed from a psychosocial understanding of autism and a subjective constructivist approach, and the implications of the research were discussed.
\end{abstract}




\section{Introduction}

"Long long ago

Where nothing was there

And God bored with himself

He [sic] made everything

Then he got bored

With everything that was perfect

And so planned to make some distortions

So he made some like me

Who as they say have lost their minds

As I sat on the swing in the playground

The teacher's words tossed in the air

Like bubbles of soap all around me

I did not play with them by waving them away

But I tried to feel them by waving them in and out

When I walked out the classroom

The tail of words followed me

Words made of letters

Crawling like ants

In a disciplined row."

This poem was written by Tito Rajarshi Mukhopadhyay (2011, The Mind Tree, pg 205) when he was between eight and eleven years of age, a gifted boy who was diagnosed with autism when he was a child. His creative writing abilities baffle people across the globe, and 
communities around the world have commended him and his mother, for the role that she played in educating Tito. Reading the beautiful and insightful poems by Tito gives us a window into the minds of the child with autism, their thinking, their struggles, and their sources of happiness. It also sheds light on the relationship a child might share with their mother, especially one like the persistent, unrelenting, and tenacious force that Tito's mother was. His book The Mind Tree was a driving force behind the conception of this paper understanding the experiences and narratives of parents who have children with autism.

Through personal experiences during internships and fieldwork, I was drawn to this topic of research. While working in a child therapy centre, I saw multiple instances where the parents of a child diagnosed with autism went above and beyond in their mission to improve the social engagement and motor skills of the child. In one case, I saw a father, who accompanied his son to the centre for more than five hours every day, making his son walk around in the waiting area to get him some extra motor movement practice. I saw multiple mothers breaking down in front of the psychiatrist while talking about the diagnosis of autism, or the challenges that they had to face while raising their child. I also saw many fathers, belonging to lower income families, saving up every penny to pay for the very expensive interventions at the clinic. It made me realize that the effort that parents put into caregiving is immense and unimaginable. I had always been motivated to work in the field of child therapy, but this pushed me to understand the experiences of the parents, and realize the great role that they play in the upbringing of the child and the prognosis of autism.

The present study aims to answer the following research questions, keeping in mind the socioeconomic and cultural context of the participants:

1. What is the understanding of autism in parents, and how has it changed over time?

2. What impact did the experience of autism of the child have on the parents? 
3. How did the parents react to, respond to and cope with any changes resultant of the autism of the child?

It is necessary to understand the psychological formulation of autism before diving into the experiences of the parents. The autism spectrum disorder is classified as a neurological disorder with behavioral symptoms under the Diagnostic and Statistical Manual of DisordersEdition 5. The criteria for diagnosing it involves "Persistent deficits in social communication and social interaction across multiple contexts". This may include deficits in social-emotional reciprocity, deficits in non-verbal communication behaviors, and deficits in developing, maintaining, and understanding relationships. The second criterion is "Restricted, repetitive patterns of behavior, interests, or activities". This involves stereotyped or repetitive movements, insistence on sameness and ritualized patterns of behaviors, highly restricted and fixated interests, and a hyper or hypoactivity to sensory input or unusual interests in sensory aspects of the environment (at least two out of these four need to be present for a diagnosis). These symptoms must be present in the early developmental period and should cause significant impairment in areas of current functioning. The presence of these symptoms must be there in early childhood, even if they do not become fully manifest until social demands exceed limited capacities, and should be impairing to everyday functioning. The DSM has also specified certain severity levels of the Autism Spectrum Disorder given in Table 1.1. 


\section{Autistic Disorder}

Revised January 26, 2011

\begin{tabular}{|c|c|c|}
\hline Severity Level for ASD & Social Communication & $\begin{array}{l}\text { Restricted interests \& repetitive } \\
\text { behaviors }\end{array}$ \\
\hline $\begin{array}{l}\text { Level } 3 \\
\text { 'Requiring very substantial } \\
\text { support' }\end{array}$ & $\begin{array}{l}\text { Severe deficits in verbal and nonverbal } \\
\text { social communication skills cause } \\
\text { severe impairments in functioning; very } \\
\text { limited initiation of social interactions } \\
\text { and minimal response to social } \\
\text { overtures from others. }\end{array}$ & $\begin{array}{l}\text { Preoccupations, fixated rituals and/or } \\
\text { repetitive behaviors markedly interfere } \\
\text { with functioning in all spheres. Marked } \\
\text { distress when rituals or routines are } \\
\text { interrupted; very difficult to redirect } \\
\text { from fixated interest or returns to it } \\
\text { quickly. }\end{array}$ \\
\hline $\begin{array}{l}\text { Level } 2 \\
\text { 'Requiring substantial support' }\end{array}$ & $\begin{array}{l}\text { Marked deficits in verbal and nonverbal } \\
\text { social communication skills; social } \\
\text { impairments apparent even with } \\
\text { supports in place; limited initiation of } \\
\text { social interactions and reduced or } \\
\text { abnormal response to social overtures } \\
\text { from others. }\end{array}$ & $\begin{array}{l}\text { RRBs and/or preoccupations or fixated } \\
\text { interests appear frequently enough to } \\
\text { be obvious to the casual observer and } \\
\text { interfere with functioning in a variety of } \\
\text { contexts. Distress or frustration is } \\
\text { apparent when RRB's are interrupted; } \\
\text { difficult to redirect from fixated interest. }\end{array}$ \\
\hline $\begin{array}{l}\text { Level } 1 \\
\text { 'Requiring support' }\end{array}$ & $\begin{array}{l}\text { Without supports in place, deficits in } \\
\text { social communication cause noticeable } \\
\text { impairments. Has difficulty initiating } \\
\text { social interactions and demonstrates } \\
\text { clear examples of atypical or } \\
\text { unsuccess ful responses to social } \\
\text { overtures of others. May appear to } \\
\text { have decreased interest in social } \\
\text { interactions. }\end{array}$ & $\begin{array}{l}\text { Rituals and repetitive behaviors (RRB's) } \\
\text { cause significant interference with } \\
\text { functioning in one or more contexts. } \\
\text { Resists attempts by others to interrupt } \\
\text { RRB's or to be redirected from fixated } \\
\text { interest. }\end{array}$ \\
\hline
\end{tabular}

Table 1.1: Severity levels of Autism Spectrum Disorder in the DSM-5.

According to a report by the Centre for Disease Control, the prevalence of Autism spectrum Disorder around the world is between 1 in 500 to 1 in 166 children. Research around prevalence of ASD in India has been a long journey, and most researches have not been able to confirm the incidence rate in children. The reasons for this were stated as the refusal of parents to participate in the study, lack of awareness in rural populations, stigma surrounding childhood mental health problems, underrepresentation of adults with Autism, and the lack of a singular comprehensive tool for screening for ASD. However, a metaanalysis by Chauhan et al (2019) done on four major prevalence studies put the rate of prevalence of Autism Spectrum Disorder in India as between $0.9 \%-1.1 \%$ for children aged between 1-18 years. According to a report by the Rehabilitation Council of India, the incidence rate for autism is approximately 1 in 500 people in India. 
Over the years in mainstream psychology, Autism has been looked at from a neurological, cognitive, and behavioral lens. Historically, Kanner (1943) was the first to identify autism (he termed it 'early infantile autism') in children when in a study of 11 children, he noted a certain lack of interest in any caregivers and observed "obsessiveness, stereotypy, and echolalia". Previously Bleuler (1911) had used the term autism to refer to childhood schizophrenia. Kanner attributed the child's autism to parents of the child, who were "highly organized, professional parents, cold and rational who just happened to defrost long enough to produce a child". Thus, the best treatment suggested was to remove these children from under the care of these cold parents. In the 1960s, these treatments were opposed majorly, by parents involved in the field of autism study in a professional capacity, and years of research has now discarded this view and believe autism to be of biological origins rather than psychological origins.

The theoretical understanding underlying this research is that of the Family Systems Model, inspired by Ludwig von Bertalanffy (1976). He first talked about the General Systems Theory in the 1920s, which talks about the importance of 'systems', which are bounded sets of interrelated components (Bertalanffy, 1976). This started to influence the work of anthropologists like Gregory Bateson, Don Jackson, John Weakland, and Jay Haley in the 1950s, who used the systems approach to understand the functioning and dynamics of families with members who had schizophrenia. Laszlo, in 1996, then moved it forward, explaining how the Family Systems Theory focussed on the relationship among the parts of the system and how these parts function together. A family consisted of a system, of which the members are interrelated and interdependent parts, which organize themselves into a unit. As early as in 1976, Bertalanffy talked about how the family is seen as transactional, where each member contributes to and makes up the whole. If we were to look at ASD from the lens of the Family Systems Theory, the influences of all the aspects of the family should be 
considered, and the individual with ASD should be understood within the context of the family rather than just as an individual. The entire family gets impacted by the daily pressures of taking care of a child with ASD, and are faced with important life tasks and life changes. For instance, parents may have to move, change jobs, or there might be tension between the parents due to the unequal diffusion of responsibilities. The sibling might feel uncared for, and less attention might go to the needs of other members of the family. Other interpersonal relationships like those with distant relatives, neighbors, friends, and peers may also be impacted. According to Chaddha and Deb (2013), due to Indian society being more collectivistic in nature, the family forms the focal point in the discourse of caregiving, and face greater burden of caregiving than their counterparts in the Western society. What stands in question is the ability of the family to continue to function, and it cannot be understood by separating the roles of each of the family members. Instead, it becomes important to look at the situation through the family systems lens and address the needs of the entire family, especially in the therapeutic process.

According to the family systems theory, the family may comprise multiple subsystems that each have dynamic and unique characteristics. However, given the constant need for the parental unit in the family (especially for the child in the family), it becomes important to focus on it the most in this regard.

In India, there is also a growing shift from joint family systems to nuclear family systems, wherein the parents bear the major effort for caregiving. Additionally, the parental unit, being the primary caregivers of the child, not only care for the needs of the child but have other overlapping roles as well. The father may be the sole breadwinner for the entire family, often burdened with the financial needs of the members, and the mother may be performing multiple roles of taking care of the house, taking care of other children, taking care of elders in the family, and often juggling this with holding a job. Desai et al (2012) spoke of how very 
sparse literature exists in the area of parental experiences with ASD and how the available literature paints a picture of the child's autism causing severe challenges in the parenting experience. Thus, their narratives become extremely important in the way the child is brought up, and the progression of ASD.

Children on the spectrum are often in need of severe care, and there is very high dependency as compared to neurotypical children of a similar age. Even as these children grow up, there is a possibility for persisting dependency due to lack of communication abilities, emotional intelligence as well as bodily control. The need for the primary caregivers exceeds its typical pattern, often going up to adulthood as well. Even though cases vary in severity and thus in consequences, the effect of the need for extended care on the caregiver is uncontested. However, there is not a lot of literature present on the subjective aspects of parenting in these cases, and the sparse literature that exists mostly focuses on quantifiable measures.

The experiences of the parent's vis a vis the child as well as with their environment become important in this context, and it becomes equally important to understand experiences or feelings across a diverse range of parents of children with autism. Not only would it help the growth of the child in the long run if the parents have a cathartic experience of sharing narratives, it may also hold greater importance in the space of therapeutic interventions. 


\section{Literature Review}

The present study aims to study and understand the experiences and narratives of parents of children who have been diagnosed with autism, and takes a psychosocial perspective to look at these narratives. Before doing so, it is important to view the previous literature available in this area of study, and how it feeds into the present research.

1. History of Autism Spectrum Disorder:

Autism spectrum disorder has a wide variety of literature surrounding it, and immense research efforts have gone into studying its causes, symptomatology, and interventions for treatment. However, in the Indian context, there is sparse literature that exists in the sphere of people and families affected by ASD. It becomes imminent to firstly understand the history of Autism Spectrum Disorder, around the world, and especially in the Indian context.

The term autism comes from the Greek word "autos", which means self. It translated to "being with one-self”, and was used to denote self-isolation in people first by Swiss psychiatrist, Eugen Bleuler. He used it to refer to "autistic withdrawal of the patient to his fantasies, against which any influence from outside becomes an intolerable disturbance". The definition of the term says a lot about its understanding, symptoms, and perceptions. Children diagnosed with autism show a lack of social communication, often interpreted as an inclination towards being alone, and are even isolated away from mainstream society because of such misconceptions. The DSM-5 criteria for the diagnosis of Autism Spectrum Disorder, and it's slowly increasing awareness and acceptance holds a lot of history behind it. After the usage of the term autism to mean childhood schizophrenia by Bleuler, Hans Asperger(1938) and Leo Kanner(1943) separately formulated the symptomology of a disorder, central to which was social communication and insistence on sameness in the child, and which came to be known as Autism. Despite ongoing research across the world saying otherwise, it took till 1980 for the DSM-III to differentiate childhood schizophrenia from autism. A diagnostic 
checklist was provided in the DSM-III-R in 1987, and the DSM-IV went on to classify Autism into various disorders like Asperger Syndrome. Rett Syndrome, Childhood Disintegrative Disorder, and Pervasive Developmental Disorder-Nor Otherwise Specified. However, only in the DSM-5 was it recognized as an individual having developmental delays or lacks (in social communication and repetitive behaviors) of varying severities, thus classifying it as Autism Spectrum Disorder.

In India, as early as 1943, a Viennese pediatrician, A. Ronald, in Darjeeling talked about "difficult children, and how they were not very backward than average children, could be trained, but showed certain atypicalities in sensitivity, inclination, and volition (Ronald, 1944). Some of the symptoms that he wrote about matched those written by Kanner, though the term autism is not mentioned. Up until 1980, the number of professionals and centers diagnosing and treating autism was very low, and a majority of professionals believed it to be a rare and untreatable disorder (Daley, 2004). Only in the 1990s did awareness increase, with the parents leading the charge to build organizations, centers, NGOs, and in turn, representation for their children with autism.

\section{Importance of Primary Caregivers:}

The noticing of symptoms is extremely culturally bounded, as are the perceptions about child development. According to Juneja and Sairam (2018), parents in the first two years of life are more concerned with motor development, which can be normal for many children with ASD. Additionally, certain cultural influences come into play. A quiet child might be seen as well-behaved, and the parents might even be thankful for having a less troubling child. Even an over friendly child who greets all strangers may be considered respectful. People coming from a lower socioeconomic position, and people in rural areas often permit and accept certain levels of hyperactivity and atypicality in children. An instinct to dismiss 
any thought of abnormality by the parents to escape the social stigma surrounding it, as well as rationalization of certain delays with reasons like delayed language development in boys, family history of delayed language development and even reassurance by relatives acts as a hindrance to seeking of help. So much so, that it is estimated that Indian parents and families become aware of and seek professional help 6 to 10 months later than parents in the United States (Jain et al, 2013; Samms-Vaughan, 2014). Furthermore, actual diagnosis and starting of interventions are further delayed by 14-24 months due to lack of awareness, lack of medical and psychological facilities, incomplete or misdiagnosis, and even disbelief by parents and their tendency to take multiple opinions (Jain et al, 2013; Samms-Vaughan, 2014).

- Attachment Theory- Given that the primary caregivers of children are their parents, research over the years has extensively talked about the importance of parenting in both neurotypical children as well as children with ASD. A good starting point would be to look at the research done by John Bowlby, commissioned by WHO in the 1950s. Documenting his research, his monograph Maternal Care and Mental Health concluded that to grow up mentally, "the infant and young child should experience a warm, intimate and continuous relationship with his mother (or mother substitute) in which both find satisfaction and enjoyment" (1951, p.13). He also looked at it from a socio-economic frame of reference and said that "Just as children are absolutely dependent on their parents for sustenance, so... are parents, especially their mothers, dependent on a greater society for economic provision. If a community values its children, it must cherish their parents" (p.84). He underscored the importance of interpersonal relationships of a child by saying that formation of an ongoing, warm relationship was crucial to the child's survival and healthy development as the provision of food, child care, stimulation and discipline (WHO, 2004). 
The theory of attachment presented by John Bowlby acts as a baseline for the healthy development of a child. However, some of these developmental capacities are not present in children with autism. In a study by one of Bowlby's associates, Mary Ainsworth (1972), she listed certain behaviors that described whether an attachment between the caregiver and infant has been formed. They were called 'attachment behaviors' and included crying, smiling, and vocalization differently towards the caregiver, orientation, and attention towards the caregiver, following the caregiver, clambering over exploration of the caregiver, and happiness when reunited with the caregiver after separation. As is evident from the clinical presentation of autism, many of these tend to be missing from the behaviors of the child with autism. In a study by Rutgers (2006), it was found that children with ASD showed significantly lower attachment security towards caregivers than children without autism. The role and importance of caregivers in such a scenario become doubly important to study.

- Psychoanalytic perspective- Psychoanalysts have also time and again talked about the importance of the caregiver. Theorists like Melanie Klein, and Donald Winnicott theorized how babies had an inborn sensitivity to the emotions of others, and that their interactions with the carers were highly significant. Insensitive care like neglect or abuse could distort or delay the child's development (Fraiberg \&Fraiberg, 1980; Spitz, 1945; Spitz \& Wolf, 1946). According to Winnicott (1965), the mother's contribution is essential, and mutual love and care are important for the child to develop emotional security and confidence. This can be attributed to the infant forming mental representations of the world and of itself during this time (including self-concept), and these representations have a role to play in the child's later motivations and perception of experiences (Walters et al., 1991). Winnicott (1965) described the caregiver's role at the early stage of infancy as "primary maternal preoccupation", where the caregiver is greatly attuned to and aware of the needs, behaviors, and emotions of the child, which allows them to adjust and respond to its needs appropriately. The caregiver 
creates a "holding environment", which includes both physical as well as psychological protection and containment. There is a representation of being understood and validated through the infant's experience of empathetic care and warmth.

- Cognitive and cultural perspective- From a cognitive, cultural, and developmental point of view, various theorists have also talked about the importance of parenting or caregiving in the development of the child. Vygotsky, in his theory of cultural development (1981), speaks of "a zone of proximal development" existing in young children, referring to a potential level of cognitive functioning achievable by the child by the guidance and collaboration of more experienced, perceptive and responsive adults. His theory especially points to its applicability in the Indian cultural setting, where "elders" are seen as sources of wisdom and knowledge, and children are taught to emulate them as much as possible. According to Bruner \& Sherwood in 1983, early interactions between caregivers and children, where the parents often attribute meanings to the utterances and gestures of the child, predispose the infant to the development and acquisition of language. Thus, parents who often babble along with the child, or when they base their response on the utterances of the child form a better bond as well as contribute to the child's healthy cognitive development. Though these are in no way a comprehensive account of literature and aspects of study in the caregiver-child relationship and its effects, the aspects which are relevant to the present study have been listed.

- Indian Perspective- While researching for studies relating to autism and parenting, it became evident that the biomedical model of mental disorders had often led researchers and clinicians to label autism as a chronic mental illness, disease, or disability. Going forward in the review, autism might be seen from this point of view according to the study being reviewed, but it does not represent my views in this regard in any manner. In the Indian context, Dalal (2002) talks about how central a role does the family play in providing care, 
sustenance, and support when a dialogue around disability takes place. This care, especially that of mothers, sisters, daughters, and other females of the family, often goes unacknowledged and underappreciated, becomes a form of informal labor. According to Das and Addlakha (2001), the locus of the disability does not lie within the body but permeates outside the body into family, kin, and community. Vaidya (2016), a mother of children with autism, added that the family and caretakers often have to become a "voice" for the disabled individual and become a bridge between them and society. It has been pointed out that approximately $90 \%$ of the people with chronic mental illnesses in India live with their families, which play crucial roles in routine care, medical care and support, financial support, as well as managing challenging behaviors and symptoms (Chaddha, 2014). This is reflected in the kind of responsibility that the family, and especially the mothers have to uptake in the upbringing of the child, where personal suffering as a result of these responsibilities is considered natural and is to be worn like a badge of honor. In a study by Crowell et al., (2019), it was also explored how mothers often have to take up roles of therapists, educators, special educators, psychologists, speech therapists, etc., going beyond what their traditional role as mothers would be, and often need to develop skills which mothers of neurotypical children do not. Given that India has a growing child-centric trend in families, where the child becomes the gatekeeper of the family's collective ambitions, and goals, it exacerbates the responsibility of "excellent care" by caregivers.

3. Effects, risks and the burden of caregiving:

This brings us to the struggles and the risks associated with being parents of children with autism. There has been considerable literature around the same, and many authors have written about the physical, psychological, emotional as well as social stressors that become a part of parenting or caregiving a child on the spectrum. The beginning point for this started 
with Kanner and his psychoanalytic perspective of "refrigerator mothers". He observed and wrote about how parents of children with autism tend to be aloof and even relatives showed certain atypical traits. Asperger also wrote about similar observations in his work around that time. According to Grinker (2007), this may have been an indicator of a genetic component in autism, but the observations were taken at face value, and the parents and mothers, in particular, were stated to be the cause of the child's autism. Kanner wrote that parents of these children kept them "neatly in a refrigerator that did not defrost", damning the parents to a life of guilt, and isolation from the rest of the society. The psychoanalytic explanation provided by Bruno Bettelheim, a former prisoner of Nazi concentration camps, wrote in his book The Empty Fortress (1967), comparing autistic children with inmates of Nazi camps, and their mothers with Nazi officers. He proposed that parents of autistic children were mentally impaired and reacted in abnormal ways to the normal behaviors exhibited by their child. As a result, the child became aloof and withdrew from the social world, much like the prisoners of concentration camps (Feinstein, 2010). A cycle of rejection and withdrawal would result in the child retreating into "chronic autistic disease". He stated that the only way to treat the same was to take the child away from the pathological parenting. In most of these understandings about the causes of autism, the mother was held more responsible than the father, as she spent the most time caring for the child, and had more responsibility for the upbringing of the child. The father was seen more in a financially supportive role. Moving beyond these clearly demarcated roles was considered (and in some places in India, is still considered to be abnormal, and a cause for the child's pathologies. Even though multiple studies have proven that the behaviors or personalities of parents do not lead to the child developing autism, this notion has permeated society's understanding of autism. Parents, and especially mothers, continue to be blamed for any and all issues relating to the child. Working, education, and professional mothers have to bear most of the brunt of this thinking, 
as they are accused of "defecting" the child by focussing on 'selfish professional goals' rather than her innate responsibilities of being a 'capable and nurturing mother'.

It is logical to infer from this understanding of caregiving that since parents are to be blamed for the child's autism, there also exists a burden on them to take up total responsibility for the care and to often choose their child over personal well-being. In a paper on the Burden of Caregiving for children with disabilities in India, Upali Chakravarti (2008) has written about how the burden for caring falls on the immediate family, and specifically on the mother. There is a lack of social support, networks, and even financial resources, which put an additional burden on the family. Taking care of the child is not only physically exhausting but can also mentally exhaust the parent to the extent of not wanting to do it anymore. It may lead to deterioration of the self. Care for a disabled child is often expensive to outsource to someone outside the family, and is often considered menial and dirty work. Many parents have to negotiate between careers and caregiving, and there is often a sacrifice in the professional front for the mother and an abandoning of caregiving responsibilities by the father. This is of course, propagated by the gender roles associated with being a mother and father. Quantitative studies carried out in the West have also shown that parents of children with disabilities show much more stress than parents of typically developing children and that mothers show higher levels of stress than fathers (Mandleco et al., 2014). Another study identified symptom severity, additionally piled-up demands, and the lack of social support to be indicators of increased levels of burden in parents who had received a diagnosis for ASD for their child in the past six months (Stuart \&McGrew, 2009). A study by Kumar et al., (2013) also found that the quality of life of parents of children with autism was impaired across all parameters of the WHO Quality of Life BREF Index.

4. Narratives of parents and caregivers of children with autism: 
All of the above-cited literature points to the need to assess the experiences and narratives of parents of children with autism for their betterment, as well as the well-being of the child under their care. I would now like to review research which has also examined these narratives.

Roper and Allred (2014) researched the caregiver burden in parents, and found that mothers reported higher levels of caregiver burdens than fathers, and that parents of children with autism showed higher levels of caregiving burdens than parents of children without autism.

A study by Willis (2014) explored the narratives of minority parents of children with autism. It was found that parents had significant difficulties in caregiving, and factors such as religion and spirituality, presence of a strong self, shared support, amongst others, played a key role in the parents 'pushing through' in light of challenges. In 2016, a study by Loukisas and Papoudi also studied the experiences of mothers of children with autism, and their journeys from looking at autism as a 'tragedy' to acceptance and advocacy for their child. Altiere and von Kluge (2009) spoke of how parents of children with autism moved on a journey of confusion to devastation, and finally to mobilising resources to help their child, and eventually describing positive experiences and learnings from their narratives.

A study by Gobrial (2018), it was found that mothers found life with their child's ASD daunting in nature, and it had a negative impact on their social life and emotional well-being. The mothers spoke of the financial strain, personal sacrifices, and social stigma that came with parenting a child with autism.

In 2019, a study by Shorey et al talked about the Asian experience of parenting a child with autism, which was close in value to the Indian context. The parents in the study were interviewed and themes of familial and social support, coping strategies, future hopes and diversity in their journeys emerged from their narratives. 
In the Indian context, a study by Brezis et al., (2015) carried out in New Delhi, examined the narratives of parents of children with autism before and after a Parent-Child Training Program at Action for Autism. This program was aimed at the empowerment of parents, their education regarding autism, and encouraged the acceptance of their child. Data was collected through the Five Minute Speech Sample narrative method (Magana et al., 1986), where they were given a short prompt and asked to speak for five minutes without interruptions. It was found that after the program, the parents focused more on the future than their perceptions and comparisons to normalcy, and started to understand themselves and their relationship with the child. This research became an inspiration behind the present study, and was used to understand the applicability, importance and need for examining the narratives and experiences of parents of children with autism. 


\section{Ontology, Epistemology and Methodology}

The aim of the present research was to examine the narratives of Indian parents who have children with autism. This particular topic was chosen because of my inclination towards understanding the subjectivity of primary caregivers and how their experiences are interrelated and interdependent with that of their children diagnosed with autism and vice versa. The central argument that drove me to pursue it was a curiosity to understand the experiences of these parents' experiences, and to delineate their struggles and motivations; I

observed through my experiences that these individuals often have superhuman resilience and abilities to put in efforts for their child.

Before the beginning of any research, it becomes essential to ground oneself in an epistemological, ontological, and methodological position. It determines the nature of inquiry and how it needs to be practiced. They may be thought of as belief systems into which one grounds oneself before the beginning of the acquisition of knowledge. The positioning of the present research is discussed below.

\section{Ontology}

My inquiry was into the experiences and narratives of the parents, implying a subjective nature of reality. I conform to a dynamic model of personal development, wherein, the experiences of one's life, including their socioeconomic, cultural, and religious positioning in the world makes them who they are. It is then natural to assume that each person is unique, and reacts to, responds to, and is affected by similar circumstances in unique ways. Every parent has a different background, upbringing, education, and life experiences, and each of these leads to the parent responding differently to the child's autism. The reality of their lives would be socially and experientially based as parents of children with ASD. For instance, one parent might see their life as destroyed by the child's autism, whereas another would see it as 
a learning opportunity and a way to show their devotion towards their child. As a researcher, it then becomes my responsibility to take these experiences as equally representing the 'truth' and not value one reality over another. The knowledge that is being chased is not "out there", but is constructed as an outcome of human activity, is not certifiable, and is dynamic and constantly evolving. Thus, from an ontological point of view, a position of Relativism would be held throughout the research. Guba, as early as 1990, spoke of it and assumed that multiple realities and perspectives exist in people's minds, and such an approach is the key to openness and richness of knowledge acquisition.

\section{Epistemology}

As in any inquiry, it is essential to ground oneself in an epistemological position, i.e., defining the relationship between the knower and the known (or the inquirer and the knowable). In the present study, the researcher is not on the 'outside' looking 'inside', but is playing an active role in shaping the narratives of the parents. It is essential to note that the term "participant" is used rather than "subject", since the latter projects a more positivist and experimental paradigm. The parents in the study are considered voluntary participants who have something of value to contribute using their human subjectivity. The contents of the questions, the relationship, and rapport between the interviewer and the participant would shape up the entire narrative. If questions about a certain subject are not addressed, those parts of the narrative would not come into the light. Only infinitely extensive research would be able to take into account every single possible variable that falls under the narrative, but such research is impossible. Even during analysis and interpretation of the narrative, the bias of the researcher would need to be considered, as certain ways of thinking would influence what is highlighted, and what is not. Thus, a certain level of subjectivity and bias would enter 
the area of research and the epistemology would be Subjectivist, as the values of the researcher would mediate inquiry.

\section{Methodology}

Where methodology is concerned, to understand the narratives of individuals, a Hermeneutic and Dialectic approach needs to be taken. This involves understanding of the narratives in-depth and as accurately as possible (delineating them verbatim) and trying to bring together the different narratives into as much consensus as would be possible. This would be required to make the research more understandable and applicable in its usage. However, it needs to be noted that only partial consensus is possible between constructions, as each narrative would be quite different from each other. Certain themes may be drawn out of the narratives to improve the reader's understanding. Thus, with these components, the research falls into the Subjective Constructivist paradigm. This method emphasizes the significance of the researcher as a filter for information that is obtained from the participants. The interaction between the participants and the researcher influences how the information is perceived, analysed, and reported.

For the present research, the method of inquiry was chosen to keep in mind the sensitivity around the area of research, the comfort levels of parents, as well as an attempt towards the maximum confidentiality of participants. After reviewing past literature, a broad range of themes was chosen to be focussed upon. These included upbringing of participants and childhood experiences, life in the marital dyad, relation with the child, emotional responses to diagnosis of the child, social and familial support, change in personality over time, and hopes for the future. Given the quarantine situation and the nationwide lockdown in India due to the mass epidemic of Coronavirus, a last-minute addition was that of the theme of the impact of 
quarantine with the child on the parent. A basic set of questions was formed as the proposed interview protocol.

\section{Participants}

Due to the nationwide lockdown, it became difficult to reach potential participants through organizations like Action for Autism, since they had temporarily closed down operations. Additionally, as a researcher, I felt uncomfortable disturbing parents and asking them for their time during what I expected to be an already overwhelming period of time. Thus, I posted messages on Facebook support groups for Parents with children who have autism in India (namely 'Autism-India' group, 'Autism Parents Support Group-India', and 'Parents of Autistic Children' group). These messages clearly stated where I was from, the purpose and aim of the research, the need for the research, the time requirements for the participants, and promised voluntary participation, confidentiality, and a collaborative research process. A few responses were received through these messages, out of which 2 parents ( 1 mother and 1 father) became participants. I was also reached out by some practitioners, who put me in touch with parents of children they worked with, whom they thought would benefit from talking about their lives, and 2 of these parents agreed to participate in the research (1 mother and 1 father). Additionally, I also contacted the Forum for Autism group, which works on building a platform for parents of children with autism to connect with each other and gain social support. Two parents (1 mother and 1 father) from this group became final participants in this research. Before agreeing to be participants, the parents were sent informed consent forms (Appendix A), which delineated the objectives, aims, and method of research, as well as informed them about the recording of the interviews. Due to the lockdown, physical signatures of the participants could not be taken, so digital signatures or verbal consent was taken. A few participants who did not have access to their email were sent the consent form 
through WhatsApp. One participant who did not own a smartphone explained every aspect of the consent form on the phone, and verbal consent was taken.

The ages of the participants ranged from 31 to 47 years, and they resided in different metropolitan cities of India. They were all well versed in either Hindi, English, or both. Their occupation and socioeconomic status were varied. A balance between mothers and fathers was maintained, with three participants of each group. This was done keeping in mind the extensive literature on mothering children with autism, and the scarcity of research done on fathering the child with autism. Pseudonyms were used for the participants to protect their privacy.

\section{Method of Data Collection}

To assess the basic demographic data as well as gain information about the family, child, diagnosis of the child, and special needs of the child, a short questionnaire with 15 questions was formed (Appendix B). The answers to this questionnaire gave me an entry point into the participant's life and reduced a perceived awkwardness before starting the interview. I also felt that this was a more sensitive way of asking about diagnosis than a mechanical inquiry during the interview. A few parents also said that the questionnaire gave them a chance to understand what the interview was going to be about.

Based on the responses of the participants, the interview questionnaire was modified. At a time of convenience for both the participant and the interviewer, a time for the interview was decided. Even though the research had initially been envisaged to have face-face-face interviews, it was not possible to do so due to the lockdown. Keeping in mind the issue of internet access, online video calls were also not feasible. Thus, phone calls were decided as a constant means for data collection. The phone calls were recorded. At the beginning of the interview, the contents of the consent form were repeated, and permission to record the interview was taken again. The interview was semi-structured, and aside from the basic 
interview protocol, follow-up questions were also asked depending on the responses of the participants. The length of the interviews ranged from $45 \mathrm{~min}$ to $125 \mathrm{~min}$. The participants were sent the recordings of the interviews and were asked if they wanted to retract any statements, to ensure as much collaboration between the participant and the interviewer. The transcribed interviews were also sent to the participants.

\section{Method of Data Analysis}

The method of data analysis was chosen keeping in mind the subjective nature of the data, and the need to keep the data as authentic as possible. Thus, Narrative Analysis given by Catherine Riessman (2005) was chosen to analyze the data. As the interviews were chronological and were in a storied form, they were treated as oral narratives centered around their experiences with their child's autism. According to Riessman, narratives require interpretations, and an attempt was made to do so without losing the essence of the parents' life stories. Within the narrative analysis approach, a thematic analysis technique was followed. The emphasis lies on "what" is spoken more than "how" it has been spoken. It subsumes that language is a direct and unambiguous route to meaning. Certain themes are drawn, connecting different narratives, and making them as generalizable as possible. Individuality is maintained while simultaneously connecting life stories and experiences based on certain commonalities. Focus on the content of the story does not mean that the way of communication is ignored. Wherever relevant, nonverbal communication has been assessed. The reason for choosing the thematic narrative analysis technique was twofold. Firstly, the objective of the research was to examine and understand the narratives of parents and apply this understanding in clinical or social settings. The thematic narrative analysis provided a very grounded base to do so. Secondly, nonverbal communication and the act of telling the story could not be analyzed much due to the interviews being held over the phone. Facial expressions, body language, etc., could not be studied in such a scenario. Thus, the 
Narrative Thematic Analysis technique, as given by Riessman, was used to analyze, interpret, and create meaning from the data. The themes that emerged from the analysis were 'Lack of Knowledge about Autism', 'Emotional Upheaval of Parents', 'Role of Mothering', 'Role of Fathering', 'Child-centric Lifestyles', 'Presence of Social Support' and 'Effects of Sociocultural and Economic Positioning of the parents'. 


\section{Discussion}

The aim of the study was to understand and examine the narratives of parents of children with autism. Given the primary role that parents play in any child's life, it is important to understand their lives, and how the autistic experience of the child affects them. The research was centred to finding out the parents' understanding of autism, what impact did the autism of the child have on the parents, and how did they respond to any changes as a result of it. Interviews were conducted with each of the parents, and they encompassed their childhoods, education, marriage, family life, relationship with their child, and their emotional journeys over the years.

The research grounded itself in the psychosocial approach, and the interviews were designed keeping in mind the interplay of psychological and social forces that make up for a person's experiences. The interviews were semi-structured and the language used, terminology, and way of presenting the questions were kept flexible and were changed according to the positionality of the parent. For instance, a parent hailing from a lower socioeconomic background was asked all the questions in Hindi, and terms like 'autism', 'psychiatrist', 'therapy', etc., were eliminated as they said that they had limited understanding of these terms. Since some parents did not own a computer or did not have access to the internet, it was decided that all interviews would be held over phone calls. During the interviews, my own reactions and responses to the parents' answers were noted, and an attempt was made to include this reflexivity in the writing. It was also acknowledged that each parent came from a different social, economic and cultural position, and the implications on their experiences were understood.

Using the Narrative Thematic Analysis (Reissman, 2005), themes were based on anecdotes and vignettes from the interviews, perceptions about 'how' the experiences were 
narrated, and backed by previous literature and theoretical understandings. These themes are discussed below.

\section{Themes}

\section{Lack of Knowledge about Autism in the parents}

A primary theme that emerged in the research organically was the unfamiliarity that the parents had towards autism, and how it affected their formulation and meaning of autism.

Most parents talked about how there was a lack of awareness about the term 'autism' and how they had never even heard of such a term before their child was diagnosed with it. They were either fearful of autism, or curious about it.

One mother, Anika, whose son who was diagnosed with autism almost twenty years ago said,

"There was a doctor there, who diagnosed him with autism...this was 20 years ago. Nobody knew what this term was, so she had to explain it to me. Aside from specialists, we didn't have Google or anything, it was difficult to get information" (Anika, personal communication, May 2, 2020).

Another mother, Nimisha, with an adolescent son with autism spoke about how she found out that her son needed help:

“Meri didi ne bola ki 'tere bacche mein kuch 'problem' hai'. Lekin voh mujhe bta hi nhi paayi ki problem kya hai. Hum samajhte hue bhu nasamajh the. Kyunki jab aaj tak life mein kisi ne 'social behaviour' jaise term use nhi kare hain, toh humein bhi kaise hi pta hota. Aur jab problem pta hi nhi toh usko kiske paas leke jaoon mein dikhana ke liye. Meine apni mummy ko bola toh unhone mere bete ko khadha karke dekha, baitha ke dekha, uske haath, per dekhe, aur bola ki sab theek toh hai. Unhone kaha ki 'teri didi hi zyada badhi ho gayi hain"' ("My sister has told me that my son has a problem, but she couldn't verbalize what the 
problem was. We could understand, but we were still clueless. There had been no need for us to know terms like 'social behavior' in our lives, so how would we have known? And when you don't know what the problem is, whom do you take the kid to? When I told my mother about what my sister had said, she made my son sit, stand, checked his hands and legs, and said that everything looked fine. She said 'maybe your sister has grown too much") (Nimisha, personal communication, April 25, 2020).

Rohit, a father of a 3-year-old child with Autism and ADHD symptoms said:

"When he was in playschool, his teacher told us about his lack of eye contact, and how we should consult a pediatrician or a specialist for this autism thing. That was the first time I had ever even heard of such a term...we are from a small town, village, so nobody in my family had heard of autism. We didn't even know if it's autism or not. So we started searching on the net" (Rohit, personal communication, April 20, 2020).

It is clear to see that the lack of awareness about the term had induced a sort of anxiety about the unknown in the parents. They, like most people, had not been exposed to information regarding developmental disorders. For Anika, the lack of internet led to a reduced number of resources that could be used to understand the term 'autism'. Four of the other parents talked about how the internet was a boon in terms of improving their knowledge about autism. There is much more focus on the physical health of the child than the mental, and perfect physical health implied overall lack of any issues. According to Juneja and Sairam (2018), most parents are more concerned with motor development of the child during the first two years, and the parents may not notice developmental delays in cognition or language development. It is also evident how the lack of this awareness about autism led to the parents not knowing where to seek help from. Even if the parents did feel some problem, they were often laughed out of physician clinics, or even reprimanded for being an overthinker and wasting the doctor's time. Such was the case of Nimisha when she went to a 
physician and asked if there was something wrong with her child, as had been told to her by her sister, and was scolded by the doctor for being too vague.

An important part of this experience is the role of language in the understanding of autism, where Nimisha's sister did not have the words to explain what she felt was the 'problem' with the child. In such a scenario, where the ways of explaining oneself are not available through language, the person often has to solely rely on instinct. This leads to a lack of communication in expressing one's issue to the other. These explanatory terms are not limited to 'autism', but also include terminology like 'developmental delays', 'social behavior', 'constructive play and destructive play', 'repetitive behavior' amongst others.

Those who did come to know about autism often did so through professionals like psychologists, teachers, special educators, speech therapists, etc. The parents were usually informed by the child's school about certain different or "problematic" behaviours of the child, and were told to visit either a counsellor or a psychiatrist. All the children had first been tested for hearing impairment, and only after that was ruled out were they given any diagnosis of autism. Rohit's son and Saanvi's son were both first diagnosed with ADHD, and the diagnosis was later changed to autism. The parents' understanding of the term thus came from how it was portrayed by these professionals. Rakesh, the father of a 12-year-old son with autism said:

“... he was admitted to a school. We were told that he was very, very fidgety, and he would not sit in one place and he required occupational therapy so we said okay, and we used to take him. I don't think maybe at that point that I probably did not take it too seriously. Around that time I happen to read something about autism when I started reading about autism and started mentally thinking about it. And then when you started thinking about it, you would try to see some similarities in the description that was being given, and you try and relate that to your child. And that is when I realized that Sarthak 
was showing all the textbook characteristics of being a child with autism. So even if he was, that was okay, but we needed to know whether he was a child with autism. So we decided to ask the head of the department of OT whether Sarthak had autism. She had a lot of years of experience and she was quite confident in saying that Sarthak did not show signs of autism. He had some sensory processing issues but was not on the spectrum. And we decided to trust that lady, as you would with someone who has that level of experience. And till date, we do not hold it against her because things change over time and different people may come to different conclusions. About a year later we moved Sarthak to a new school...we were called into the school and were told that your son is showing some characteristics which are not considered to be appropriate behavior at school. Yeah, so that was when we were told that we needed to consult a developmental psychologist. We took him there and the DP administered some tests and concluded that he is on the spectrum. Okay, so if you ask us. The diagnosis that he's on the spectrum came later on" (Rakesh, personal communication, May 4, 2020).

This incident, along with the experience that Nimisha had with her doctor makes it quite evident the role that professionals have. Doctors, physicians, pediatricians, social workers, and school teachers, are often themselves not aware of autism and its symptom recognition. This lack of understanding hinders communication to the parents as well. When trust is placed in the doctor, any misdiagnosis on their behalf can limit the interventions that the child can receive. Additionally, since the best way to deal with ASD is through early interventions, clinicians advise early screening and diagnosis as the ideal situation. Jain et al. (2013) found that there was approximately a 14-24 months delay in diagnosis and starting of interventions caused by lack of awareness, misdiagnosis, lack of facilities etc., in India. Thus, there is a disparity that exists between the lack of awareness about ASD and its symptoms, and the need for early intervention, which can lead to delayed development of the child. 
During the interviews, it was also seen how the perceptions and understanding of autism had changed for the parents over time. This was attributed to either education about autism, experiences with the child and with other parents, as well as acceptance of the situation. Rakesh spoke about a course that he had undertaken a few years prior, and how that had helped in understanding his son:

"So when I pursued this course on ASD I was made to understand that children with autism fail to develop what is called the theory of mind, and they see themselves as the centre of everything. There is some influence of this on what I'm saying. Sometimes Sarthak does not wait for anyone. When he calls for someone, he needs the other person to be at his beck and call immediately. So he has very less tolerance in that aspect. He also fails to understand that there are some things that he does that someone else would also do. So if he is sleeping in the night, he cannot see that other people also sleep. So maybe he considers himself to be the centre of everything. So everything and everyone around him has to dance to the tune of whatever he is playing. Maybe that's how he perceives the world around him. Though he is quite okay with things not going the way he wants them to go. He continues to be a happy child in that way, even when things might not go how he wants them to go. So if he wishes someone good morning and they don't wish him back, he doesn't seem to take it to heart. And that is evolved thinking in my opinion. Not many people may be able to digest that. Yeah, but this is different. Maybe he doesn't understand on. Maybe he's beyond that. That's why I feel he is able to get around his environment despite whatever challenges he has. He probably feels that everything is in equilibrium, and he seems to control that equilibrium" (Rakesh, personal communication, May 4, 2020).

When Rakesh talks about the 'evolved thinking' that his son, Sarthak, displays, he is coming from an educated position, where due to his understanding of psychology of the child 
and theory of mind, he is able to understand and communicate his child's perception of the world. On the opposite end of the spectrum is Parvesh, who understand his son's diagnosis in this way:

"Normally dekhta hoga voh duniya ko toh. Bachpana sa hai usmein abhi bhi. Dhyaan nhi deta aur apne mein mast rehta hai. Thodha dimaag se kamzor hai shayad. Yeh samajh bhi nhi sakta ki kya karna hai aur kya nhi karna. (He looks at the world normally I suppose.

He still has a childish nature in him. He doesn't pay attention and is lost in his own world. He is a little weak-minded. He can't even understand what he should or shouldn't do)" (Parvesh, personal communication, April 25, 2020).

Parvesh, who comes from a lower socio-economic background, and does not have a very good grasp over English, said that he did not know anything about the term autism, and thus, his own rationalization of his son, Akash's, behavior. It is often seen in India, that parents and other family members (especially the elders of the family) give rationalizations for not seeking help. If the child does not speak, they often stick to their assumption that the child would speak late, and would thus delay visiting a pediatrician or a specialist. There are some assumptions attached to hyperactivity of the child, wherein children (especially boys) who are hyperactive may be deemed merely 'naughty' or a 'trouble-maker' (Juneja \& Sairam, 2018). Children in rural areas are even given some degree of leeway in terms of how hyperactive they are. Parents often look at repetitive or obsessive behaviors of the child as 'a phase', and only as a last resort do they consult a professional. Nimisha also said that she considered her son's behaviors " $k$ hel” or play.

This has to do with how easily the parents accept the behaviors of the child, recognize developmental delays or atypical behaviors, and get intervention. After a long time of overlooking symptoms, rationalizing behaviors, and even ignoring delays, parents may come to realize the need for consultation of a professional, and the diagnosis of the child often 
introduces them to autism or changes their perception of it vis a vis their child. Desai et al (2012) found that parents may hear the word 'autism' but would not apply it to their child due to lack of familiarity or because their child was functional in other aspects of life. An RCI report about Autism in India wrote how Daley (2002) talks about how parents may attribute any delay in social interactions as part of their child's 'unique' personality, and believe their child to be more 'mature' or a 'thinker' in nature. Rohit explained his feelings after the initial diagnosis:

"Feeling was not very positive because the cases which were on the net or the video which I was seeing they were not really very helpful, I was not getting positive vibe but somehow I was able to differentiate ki matlab Laksh mein itni problem nhi thi jitna usmein describe hua tha yaa dekhne mein samajh aaya tha (that the problem that was there with Laksh was not that severe as was shown in the videos)" (Rohit, personal communication, April 20, 2020).

This comparison with other 'typical' cases of autism is quite common in parents, and parents spoke of how they compared their child to other children they saw in the clinic or online, and how that is how they decided how much of a 'problem' their child had. Over time, this tendency reduced and an acceptance of autism started to take place. Rakesh, while talking about his journey and reactions to the diagnosis, said:

"So the diagnosis did not come as that much of a shock to us, as it might to many other parents. We just thought that okay what do we need to do to ensure that he becomes better. no parent at that point in time can accept the fact that the child has some issues, but would just want the ailment on the disorder to the become better. It's only later that you realize that its not a disease or a disorder but its basically just how the individual is. So you reconcile your opinions" (Rakesh, personal communication, May 4, 2020). 
This proactive behaviour of wanting to make their child better, or to help improve the child's condition, was common across all parents. Given that autism does not have a 'cure', but is a different experience of the child, and most clinicians only help out in terms of how well adjusted can the child become, the parents have a tough time adjusting to the diagnosis. Nimisha, talking about her reaction said:

"Mein sochti thi aisi kaunsi beemaari aayi hai jisko aaj kal ke doctors or science nhi theek kar sakte.(I used to wonder what kind of an illness is this which the science and doctors of today cannot cure)" (Nimisha, personal communication, April 25, 2020).

Being told about the lack of a cure had different effects on the parents, ranging from an eventual acceptance of their child just the way they are, and seeing autism not as an illness but just as a way of being (like in Rakesh's case), to emotional breakdown and a shift into overdrive working towards 'curing' their child, as was the case with several other parents.

Autism was understood by the parents as a disorder initially, and this understanding moved towards autism being a diagnostic category. Some parents eventually recognized that autism was an experience of their child that may be different than their expectations, but that did not make it wrong. Some parents viewed it as an opportunity to support their child, and some viewed it as a reality that they would just have to live with.

Given the emotional aspect behind their understanding and perception of autism, and acceptance of their child, the next theme which emerged was regarding the emotional response of the parents.

\section{The Emotional Upheaval Experiences by the Parents over time}

Parenting a child is an emotionally demanding task that often takes the parents on a journey. There are highs and lows in any parent-child relationship, and the life of one starts to affect the life of the other in major ways. After the diagnosis of autism in their child, the 
parent can go through a myriad of emotions, varying from parent to parent. These responses depend upon the background of the parents, social and familial support, coping strategies. Despite the different manifested emotions and the different ways of coping with them, it became clear that none of the participants took the diagnosis lightly, and had a strong, if not extreme, emotional reaction to it.

In the present study, it was noted that the initial response was a negative perception of autism in all the participants. Talking about the first few days of hearing about autism, Rohit said:

"Feeling was not very positive because the cases which were on the net or the video which I was seeing they were not really very helpful, I was not getting positive vibe" (Rohit, personal communication, April 20, 2020).

Saanvi talked about when the she took her son, Ayaan to the pediatrician, he wrote the word 'mentally challenged' on the prescription along with some medication. She said:

"I was shocked and I literally cried. You can think of how painful it must have been for me because I don't remember the name of any medicine I only remember the word mentally challenged written on the paper and circled" (Saanvi, personal communication, April 27, 2020).

Due to the perceptions about not just autism, but any mental health issue in our country, the perceived prognosis of the disorder or 'illness' is already negative. People expect that having a mental disorder is debilitating and the end of any form of normal function whatsoever. Thus, initial reactions to disorders are grave and disheartening and are only assuaged by information and support provided by clinicians, professionals, and society. After this stage, the reaction is mostly proactive, aimed towards the betterment of the child. Anika, whose elder daughter has a hearing disability and younger son has autism, talks about her reactions to these diagnoses: 
"It's our child, I accepted it in a normal way, Fate hurts, but I was ready for coming consequences"... "(when the son got the diagnosis) I was shattered for 2 minutes, then I mentally prepared for the coming storm" "during biopsy when the pediatrician diagnosed him (the son) with cancer, he asked what kind of mother are you? Don't you feel like crying? I said I can cry $24 \times 7$ all the time but will that cure my son? So losing my patience or anything was not done because if I had lost my strength, then my husband would have lost too. We were each other's support system.Ek bhi dagmaga jaata toh, sab khatm ho jaata (If one of us faltered, then everything would be over)" (Anika, personal communication, May 2, 2020).

Proactive emotional responses were not based upon the reduced expression of emotions through crying, and the opposite end of this spectrum was seen in Nimisha:

"mann mein baith gaya tha ki koi beemaari hai toh darr sa laga, rona bohot aata tha, baithe baithe bas sochti thi aur roti thi...uss time ki feelings toh aap puchiye mat. Jab mein raat ko soti thi toh sote sote meri aankh se aansoon girte the aur mere husband ka kabhi pillow pe haath aata that oh voh mujhe uthate the aur bolte the ki phir aap rho rhi hain, mein bolti thi ki kya ho gaya babu ko aur joh bhi ho gaya usska ilaaj kyun nhi hai. Machine laga rhi hoti thi toh kapde dhote dhote rona aa jata tha. Pta bhi nhi chalta tha. Ek din aisa hua ki hospital se aa rhi thi, mujhe lagta tha ki koi duniya mein aisi beemari nhi hai joh theek nhi ho sakti aur ekdum shiddat se lagti thi mein Virat ke saath. Meine poori diary banayi hui thi ki jab bhi doctors mujhe koi sawaal poochte the mein hospital se nikal ke unn sawaalon pe kaam karti thi, aur harr baar mujhe lagta tha ki mujhe doctor kahenge ki tumnein yeh cheezein theek Karli toh tumhaara bacha theek ho gaya. Lekin harr baar mujhe yeh severely autistic child ka tag mil jaata tha. Ek din mujhe sir ne bataya ki autism kyun theek nhi hota...toh mein shock mein chali gayi ki agar doctor hi jab aise bol denge toh pta nhi yeh kaisi beemari aa gayi. Mein metro se aati thi aur mein 
uss din token leke baithi aur V meri godhi mein baitha tha aur meri aankhon se aansoon nikal rhe the lagataar aur mujhe pta nhi chala. Jab mera ghar aane laga, achanak sa jhatka sa laga, toh meine dekha ki metro mein jitney bhi log khade the aur jitney bhi log baithe the voh sab mujhe dekh rhe the. Mein hairaan ho gayi. Toh meine dekha ki aansoon se mere saare kapde geele ho gaye the. Phir meine aansoon poche. phir meine apne husband ko phone kiya. Meine bola zor se ki hospital mein aaj babu ko bola ki autism beemari hai aur voh beemari theek nhi hoti. Rote rote bola. Mere husband ne bola ki koi baat nhi aap ghar aayiye hum ghar pe baat karte hain. Uske baad joh log mujhe dekh rhe the unhone dekhna band kara (It was in my mind that there is some disease so I was scared, I used to cry a lot, I used to sit and think and cry...Don't even ask the feelings from that time. When I used to sleep at night, my pillow used to get wet by crying, and my husband used to wake me up and ask me why I was crying. I used to ask why had this happened to our son and why there was no cure. Even when I used to wash clothes in the machine, I used to start crying without even realizing. I used to think that there is no disease in the world which cannot be cured if I work hard with Virat. I had made a whole diary and whenever doctors used to ask me questions I used to go home and work on them. I thought that when I would go the next time, they would tell me that you have cured your son. But I used to get the tag of severely autistic. Then someone explained to me that autism cannot be cured, and I was in shock, that what kind of a disease was this. When I was coming back in the metro and Virat was sitting on my lap, I did not realize that I was crying but the tears kept flowing. When I was about to reach, I suddenly realized that all the people in the coach were staring at me because my clothes were completely wet with tears. I then called my husband and spoke loudly, telling him that the hospital had given the diagnosis again, and he asked me to come back home. Only then did the people stop staring.)" (Nimisha, personal communication, April 25, 2020). 
While Nimisha was telling me about this experience, it became quite difficult for me to hold back my own emotions, because she had verbalized the pain and the struggle that she had gone through, at least towards the beginning. Her resolve for making her son better, or for 'curing' her son was no less than any other parent, and it reaffirmed that each person has a different emotional coping strategy, and sometimes an emotion-focussed cathartic approach can go hand-in-hand with a problem-focussed approach. It also became an important part of the narrative to understand that for the most part, Nimisha's emotional breakdown stemmed from fear. She had had a fear of the unknown autism, a fear for her child's future, and even a fear for what others would say or think. Despite this, her experience and tenacity towards doing everything in her power to make her son better almost seemed superhuman.

Another emotional reaction that seemed to have been present primarily in all the fathers who were interviewed was that of frustration. It stemmed from the lack of the child's ability to do certain tasks that were expected of them, and was felt when these expectations were not managed or balanced. Rakesh talks about his initial experience with his son's diagnosis:

"And gradually we saw some issues with him, which was where the real test began, because we started seeing him struggle with interacting with kids his age and so on. And you start feeling a little bit of self-pity trying put yourself into the child's shoes. Not Being able to communicate the pain you would want. And that started becoming a problem for all of us. And also you could say that it also brings with it some of the frustration. Why is the child not able to do this stuff? And you start to lose your cool more often, which started happening to me. So the first year after the diagnosis was probably fine from my side, but I think I was not necessarily behaving like a responsible father should have, because I probably was not able to understand the... essentially, I was not able to understand him. the way he would look at things right? So if he is reading something without comprehension, maybe he doesn't want to comprehend. In a way I think I was not 
able to reconcile with the fact that he would be different. Okay, so I think that the initial viewpoint was that somehow or the other we would end up curing him. So I think gradually at least I began understanding, but somehow I feel I was not contributing my fair bit to his development. Somehow intentionally or unintentionally I was pushing most of the hard labor on to my wife. And the only thing I was doing which was detrimental was that I was losing my cool and I was shouting at him. and the child wouldn't even know why he was being shouted at" (Rakesh, personal communication, May 4, 2020). Rakesh's experience is not surprising, given the immense amount of expectations parents have from their child. It is understandable to have felt frustrated as the child does not seem to understand or comprehend what the parent was trying to make them do. This is seen as a common struggle for parents, who on one hand want to 'cure' the child, but also may not have the patience that is required for the child's betterment. Shouting, aggression, even hitting the child is quite a common practice in India for inducing discipline in any child. It is evidently even more common with children who may be slow at the uptake of information, like a child with autism. Parvesh spoke about how he would hit his child when he refused to study because that was the only source of disciplining the child available to him, and given his economic situation, it was imminent that the child studies and makes something of themselves. Even Rohit spoke of how, especially in the beginning, he would lose his cool often, and would get angry towards his son for not being able to understand something in one go. This reliance on anger as an emotional outlet by the fathers may be indicative of a dependency on 'masculine' emotions, as they may have internalized the need for aggression as an outlet since they were children themselves.

The emotional responses of the parents can be understood in light of the attachment theory given by John Bowlby, who talked about it in the 1950s, and has evolved the theory over time. He says that there is a need to form meaningful attachments between caregivers and 
children, a relationship which is warm, intimate and continuous. By forming these healthy attachments, it forms the baseline for the healthy development of the child. However, in certain studies carried out by Bowlby's associates, children with autism do not have certain capacities for forming these attachments (Ainsworth, 1972). These attachment behaviours like crying, smiling and vocalizing differently towards the caregiver, giving attention to the caregiver, happiness of reuniting with the caregiver after separation, etc., are not present in children with autism. This leads to the inability to form meaningful attachments between the caregiver and the child, thereby negatively impacting the healthy development of the child. However, since the caregiver-child relationship is symbiotic and mutual, the absence of meaningful attachments have a negative emotional impact on the caregivers as well. They are often devasted, frustrated and confused about the situation, and the lack of attachment behaviours can take away from the parenting experience.

In a study by Altiere and von Kluge (2009), it was found that most of the participant parents viewed a diagnosis of autism as a life-altering event. They struggled to accept that reality, and used words like 'depression', 'devastated', 'frustrated', etc., to describe their emotions.

Shorey et al (2019) in a study in the Asian context, found that parents' initial reaction to a diagnosis of autism consisted of a wide range of emotions, including shock, helplessness, guilt, confusion, anger, and frustration amongst others. Gobrial (2018) also talked about his participant mothers feeling overwhelmed and helpless after their children got diagnosed with autism. These feelings were also noted in the participants that were interviewed for the present study.

Given this disparity between the mother's and the father's responses to the diagnosis, and the difference in the trajectories of their emotional journeys, it was important to understand 
the role of mothering and the role of fathering separately, taking into account their particular narratives.

\section{The Role of Mothering}

As was evident during the interviews, the mother, as the primary caregiver, played an extremely important role in the life of the child. There has been numerous literature on the effects of mothering in the child, but this theme would focus more on how the act of mothering affects the mother herself. Mothering, in this case, refers to the act of consciously and unconsciously putting efforts into upbringing the child well, focussing on their optimum physical and mental development by the biological mother of the child.

Firstly, it is important to see the perceived importance of the mother, in the eyes of both the mother and others in the family or society. Through these narratives, the influence of the mother was given paramount importance, owing to their experiences or internalizations of the notions of motherhood. Rakesh, whose wife had her own career taking off, shared this thought with her before marriage:

“... So I told that look, the some things in head I'm probably still old school and quite draconian. That if at any point we decide to have children I would expect the mother to devote a lot of time to the child because I personally feel that the mother needs to give or let me put it this way, the mother is a very important role in building the character of the child...I told my wife, that whenever we decide to have a child I would expect her to give a fair amount of time and stuff like that. And if that was something that was not going to be possible and the fact that it for the career had to be given greater degree of the importance, I know I would not mind taking the decision of maybe not having a child in the first place.... What I said was that a child is a very, very important responsibility for both of us and at no point of time would I want either of us to push that responsibility to the other. 
The child was a great responsibility and the parents have a great responsibility because if they had not wanting to take that responsibility or if we're trying to figure out some quick fixes, it is better not to bring the child at all. And I think she respected it. But I told her that if she couldn't take up their responsibilities over to things, we could do other things. Either I stay home and I take care of the child. the other is that we don't have a child or she decides to do something" (Rakesh, personal communication, May 4, 2020).

This way of thinking, that the mother had quite a big role to play in the building of the child's character, and the expectation of the mother to essentially leave her career to take care of the baby, is neither new nor rare. Some aspects of this thinking may even seem progressive, considering he informed his wife of this expectation (whereas mostly this expectation is not verbalized) and that he entertained the possibility of not having the child altogether in case she wanted to keep working towards her career, and even spoke of offering to stay home and take care of the baby himself. However, it is imminent to understand that this 'progressive' attitude is rare, and is often seen to be generous of the husband, whereas it is a given understanding that the woman should be expected to leave her career to take care of the baby. Owing to this age-old thinking, women who were working were deemed cold, distant, and aloof towards their children, and the concept of 'refrigerator mothers' was used to explain autism in children.

Each of the mothers had to put an end to their education or careers after giving birth due to the expectations of their husbands, families or society. Whereas Anika had to drop out of college because her sister-in-law refused to take care of her hearing-impaired daughter, Saanvi started working much later, when she needed the money to pay for her son's treatment. Nimisha also had to leave her job after her son was born, and she did it happily as she wanted to give herself fully to motherhood. It was quite obvious that for them, 
motherhood and a career could not go hand-in-hand, whether by personal choice or societal expectations.

The next part of the role of mothering is the reactions and emotions towards it from the mothers themselves. It is often told to young women that motherhood would be the greatest joy of all, and becoming a mother is what gives a woman's life purpose. This understanding is often internalized by many women around the world and even leads to extremities like the labelling of women who cannot become mothers as "barren" or "useless". Often, the primary purpose of marriage is also that of child-rearing. The women who were interviewed were identified by them being mothers to children with autism, so it became imminent to understand their perspectives towards motherhood. Saanvi said that during initial months of the pregnancy, she did not want a child as she wanted to spend time getting to know her husband better, but later also added:

"When the doctor announced that he was born, I was so overwhelmed. It was the best moment of my life when I heard him scream...I took care of him all the time. I wanted him to be creative. I treated the child like a child. I even followed some mom bloggers on Instagram and followed their advice. Instilling habits from the beginning makes him a good man, whatever I could do I used to do. Future I had no control over, but I could at least try" (Saanvi, personal communication, April 27, 2020).

Anika, whose first born child was hearing impaired at birth, had to face a lot of flak for producing a child with a disability. She said:

"My mother, father, mother-in-law, brother-in-law, all used to taunt me saying isko toh aise hi bacche honge (she will have kids like this only). When my daughter was one and a half years old, the torture was so extreme, I went to end myself again. Kept taking sleeping pills and went into coma for three days. My husband had also said that we will not plan for another child. But God had different plans for me because I got pregnant after that. I told 
him after three months when it was unsafe to abort, so he used to make me eat papaya and all which would drop the child. But he (her son) had to come, so he came" (Anika, personal communication, May 2, 2020).

It becomes clear in these narratives the centrality that motherhood holds for them personally as well as through family and society. Their absolute devotion to their children, willingness to give up on their professional life, or coercion to do so, is representative of the weight that motherhood holds.

Another important aspect that emerged during the interviews was the amount of labor that the mothers did while taking care of their child, especially after they got the diagnosis for autism. They often had to push aside their emotions and take a proactive approach, or try to maintain a balance between their reaction and their actions. Anika talks about her journey with her son Janak, over and above her requirements from mothering her daughter with a hearing impairment:

"(When the diagnosis was given) I was shattered for 2 minutes, Mentally prepared for the coming storm...there is some problem and I have to get ready for it...doc explained me in such a way that there is nothing to worry, keep on your hard work, everything will be fine, that gave me a lot of support...started working on him, started helping me out...giving him speech therapy, OP \& PT never took him anywhere, did from my own...Speech therapy 2 or 3 sessions only outside...Used to do all of these sessions from myself almost all the time" (Anika, personal communication, May 2, 2020).

She had to expand her role from being a caretaker and a caregiver, to also performing tasks that professionals did, including speech therapy, occupational therapy etc., and that required her to go the extra mile and make the effort to learn these new skills, which may not be required of other mothers. She also became a teacher for both her children, and had 
constantly revised her schedule to be available for and work for her children a hundred percent of the time.

Saanvi talked about how she only wanted the best for her child, and she took him to therapy centres in Delhi NCR from her hometown, which did not have the best facilities available. She took him to multiple doctors and therapy centres in her hometown as well as in other big cities and states to get the best results. While talking, she remembered and recounted names of each doctor, therapist, or centre that she had visited, along with all the medicines that she had been told about. When her husband refused to help out financially, she said:

"I was sitting only so I thought let's start working, since he (the husband) was not paying attention to the fact that we need to move and needed money and I did not want to take money from him or anyone else like my dad and I would take my child to the doctor with my own money" (Saanvi, personal communication, April 27, 2020).

She started working as a school teacher and would take her son to school with her every day, where he would roam about while she was teaching. Her devotion and efforts towards the betterment of the child were palpable through her experiences. She said that it required "rigorous efforts and it is quite hard", but even when it helps a little, it feels like it pays off. Nimisha, talking about her experience, said:

"Meine socha ki sawaal toh unhone vohi pooche honge joh baatein nhi honi chahiye ek normal bacche mein. Meine unn sabko copy pe likha, aur eye contact vaali cheez likhi, aur joh doctor ka target tha 6 mahine vaala, unn 6 mahine mein yeh target set kare. 6 mahine mein meine uska eye contact hold karane ki koshish kari. Jab voh toe walking karta tha toh uske per neeche kar deti thi, jab line banata that oh line mita deti thi, kamre mein rehta that oh le aati thi. Toh 6 mahine mein uska 2 seconds ka eye contact bann gaya. Jitni baatein poochi thi voh sab control ho gayi..Meine poori diary banayi hui thi ki jab bhi 
doctors mujhe koi sawaal poochte the mein hospital se nikal ke unn sawaalon pe kaam karti thi. (I thought that whatever the doctors had asked were things that were not supposed to happen in a normal child. I noted them down, and put a target on myself for 6 months. In the next 6 months I worked on these things. When he used to walk on his toes, I used to make him stand down, when he made lines, I used to rub them off. By the end I was able to handle all these behaviours, he even had eye contact for 2 seconds. Everything was under control. I had made a full diary and I used to maintain it properly.)" (Nimisha, personal communication, April 25, 2020).

Nimisha's experience and her relentless attitude towards improving the behaviors in her child were awe inspiring. She even talked about how she used to spend more than 12 hours everyday for 6 months at a hospital, waiting for her turn, just to get her son assessed. Her labour and her efforts were above what I could have imagined, and showed their commitment to motherhood.

The downside to this devotion is the often reverential love that the mother has for the child. It is also common for the woman to identify with being a mother more than being a woman, and this over-reliance on this identity was evident in this account given by Anika:

“When Janak's school was finished, I went into depression because I didn't have anything to do now. Till that time when they were in the school, I was fine. I was busy. But, after their school, when it was his JEE studies, he didn't need my help, so I was like I don't have anything to do. And then, at that time, the elder one, she was going through some medical condition, there I went into depression.. I took medications for 2 months, and I realised that I was too heavily dependent on them, the medications were so strong, I used to sleep all day. Then I discontinued those meds and made myself busy some other way" (Anika, personal communication, May 2, 2020). 
Her identity became so enmeshed with that of the mother in her, that she ceased to have a life beyond that. She, along with others, spoke of how they have nothing that they do for themselves or to make themselves happy. Whatever they do, they do for their child(ren). An identity crisis, and even an emotional breakdown, when separated from their children's lives, is not too far-fetched to consider in that scenario.

During the interviews, I felt like I was speaking to not just mothers or women, but to caregivers who had taken on the roles of speech therapists, occupational therapists, counselors, activists, teachers, and many such roles, all in the fulfillment of their motherhood. These features of maternal life that got highlighted have definite consequences to the lives of these women. In a study by Shorey et al (2019), mothers frequently mentioned changing their schedules, priorities and commitments to give more time to their child. Their social lives were sacrificed, and to an extent, a sense of loneliness and isolation set in.

I had a similar experience while reading Tito Mukhopadhyay's book The Mind Tree, and his experiences with his mother. The entire book is a chronology of his experiences with his mother, and the role that she played in his childhood. He wrote of the devastation and the guilt that his mother felt when he was first diagnosed, as well as the solution-oriented determinism that followed after. He also eloquently explained the experiences with his mother, where she was unrelenting in wanting the best for him, and went to great lengths to teach him writing, getting him to speak, and admitted into a school catering to children with special needs.

From a theoretical perspective, the role of mothering and the relationship between the mother and the child can be looked at from the psychoanalytic lens. In the Indian context, Sudhir Kakar has talked about the role of the mother in his book The Inner World (1978). He talks of how when the woman gets married, she has to make massive physical, mental and emotional compromises to adjust to the strange home of the husband. Culturally, motherhood 
is a path for an elevation in her status, especially if she gives birth to a boy. Owing to that, there is an intense bonding between the mother and the child, wherein the child becomes the ticket for the mother to gain respect in society. The society also starts to categorize the mothers into 'good mothers' and 'bad mothers' during these times. A child with autism may be seen as the product of a 'bad mother' in the society, thereby crushing the mother's dreams of an elevated status. The mother may then either become determined to 'cure' the child due to the unconscious need of an elevated status, or she may become resentful towards the child due to their role in decreasing the already low status that she holds. These conflicting feelings can lead to stress, confusion, frustration and even overindulgence with the child.

Loukisas and Papoudi (2016) found that mothers of children with autism tend to experience higher levels of stress, anxiety and even burnout, and can act as professionals and co-therapists in the absence of other available services.

Upali Chakravarti, in her paper about the 'Burden of Caregiving in India' (2008) talked about how women, who shoulder the major burden of caregiving have an added burden of the responsibilities of the household, and often even have to work due to financial burdens. If there is no outside support, whether from the family members, or from the healthcare and social services system, the mother's own mental and physical health can be negatively impacted. Services to provide emotional, mental and even vocational support to caregivers, especially mothers, are much needed in the Indian healthcare system.

\section{The Role of Fathering}

Traditionally, the role of the father in a family is limited to being the breadwinner, and may extend to disciplining the child. Hence, it is often assumed that the father does not play a very direct role in the upbringing of the child, and is seen as the secondary caretaker. In her essay titled 'Keeping fathers in mind', N.D.Paiva (2016) talks about how, in the Indian 
culture, the paternal function is that of the upholding of rules, dispensing of punishment, but the relationship with the father continues to be distant and intangible. Whereas mothering may be primary due to the biological dependence of the child, fathering is more cultural in that sense. Due to this, fathering children with autism has not been studied at length in the Indian context, and research in this area is limited.

During the initial research, I was motivated to include the father's own experience of parenting their child with autism, and its effects on their lives. While talking to all the participants, the mention of the father was quite discernable, and so were the different roles that they played in the lives of their children, or even in the lives of the mothers who were interviewed. The fathers mainly came off as being, primarily, the financial backbone of the family. Nimisha talked about the support that her husband gave her:

"Husband ne bola ki dekhiye mein time toh zyada nhi de sakta. Aur meine jaise bola ki mere husband thodha serious type ke hain. Unko bachon ko khilana nhi aata hai (laughing). Unse ho nhi paate hain. Unhone bola ki aapko agar paise yaa kisi aur cheez ki help chahiye ho toh mein apna jee jaan laga ke kar doonga. (My husband said that he cannot give much time to the children. And like I said, my husband is a serious person. He doesn't know how to play with children. He said that if you need any money or any other help, I will do everything in my power)" (Nimisha, personal communication, April 25, 2020).

Saanvi spoke of how she had to take up a job as though she was a single mother, because her husband refused to help her out in paying for the therapies and interventions with her son. She inadvertently spoke of the belief that the father was supposed to provide monetary support to the family. 
Due to this belief and expectations, a father might have difficulties in balancing their work and family life. Paiva (2016) talks about how on one hand, as a society we admonish the father for not being fully present in the child's life, while simultaneously putting excessive expectations on him to excel in his profession and be the sole bread earner. Parvesh also talked about his constant need to negotiate between his job and taking his son to the doctor, and how he, eventually, had to stop taking his son for special education and occupational therapy because of the amount of leaves of absence he had to take from his workplace.

"Kyunki Naukri Naukri hoti hai kab tak chutti lega inssan, koi kuch zyada bolta nhi tha zyada par khud se hi ho jata hai ki chutti nhi lete. (Because a job is a job, and just because nobody says anything much, I feel that I shouldn't take leaves)" (Parvesh, personal communication, April 25, 2020).

Another primary role of the father, as seen by the society, is to discipline. The father often acts as the authority figure and becomes the 'other' in the mother-child dyad. This was also seen in the fathers, where they talked about wanting to discipline their child, and failing to do so would cause frustration and aggression. Rohit talked about how he used to get impatient about his son not learning things, and often got angry because he kept forgetting stuff that was talked to him. Parvesh talked about getting and angry and even hitting his son quite often:

“Jab padhega nhi toh gussa hi aayega normally yahi toh hota hai. Jab padhega nhi toh aur kya hoga. Pitaya toh hogi. Pitaya toh bohot khaata hai, pehle se hi. Aur use iska dimaag toh kam nhi hoga kyunki pehle se hi aisa hi hai. (When he won't study I would normally get angry. What else? He will get a beating. He has always gotten beatings from me, since the beginning. And that won't reduce his mind, because he has been like this from before only)" (Parvesh, personal communication, April 25, 2020). 
Even Rakesh, while speaking of his son's childhood, talked about how he often lost his cool with him:

"And the only thing I was doing which was detrimental was that I was losing my cool and I was shouting at him. And the child wouldn't even know why he was being shouted at, and wouldn't even figure that out. My mother has unfortunately, always told me not to do what I was doing, but I was probably not willing to listen" (Rakesh, personal communication, May 4, 2020).

It became clear from the interviews with the three fathers that primarily, they were fulfilling the functions that society required of them- that of being a financial contributor and a disciplinarian to the child in their own regard.

The narratives of the mother's, with regard to their husbands, painted a little less positive picture. Whereas Saanvi talked about her husband's refusal to contribute financially to their son's needs, Anika spoke of how her husband decided to not have a second child at all after their daughter was born with a hearing impairment, going as far as wanting to end the pregnancy after it wasn't safe to do so. This brought me back to the 'othering' of the father from the mother-child dyad, where on one hand, it is the mother's unquestionable responsibility to raise the child, and on the other hand, the father can choose to have an emotional, physical or financial separation from the child without much consequence. These narratives were highlighted by the mothers while speaking of their husbands. Saanvi spoke of her husband's behaviour and indifference towards the needs of their son:

"When Ayaan was born, everyone was very happy except for my husband. He is a poetry persona and writes poems. When I asked him to write a poem for our child when he turned 1 year old, he did not write and till now he has not written it. He doesn't know how to express love with his family. Aside from them, he is good with everyone." 
"When Ayaan was diagnosed with ADHD (initially), he (husband) did not even pay attention even then. He kept saying ki theek ho jayega, wait karo theek ho jayega, late se bolega, log toh aajkal kuch bhi bolte rehte hain bas. (he will be ok, just wait he will be okay, he will speak late, people keep saying things like that.)"

Anika talked about how her husband dealt with their son having been diagnosed with autism and their daughter with a hearing disability:

"Starting it was a bit difficult, difficult to accept, he never used to take us anywhere, we were at home always, no function, nothing at all, but as the kids started progressing, things changed" (Anika, personal communication, May 2, 2020).

It became evident from these narratives of the mothers, along with my own personal experiences, that the role of fathering assigned by society is very different from that of mothering. Whereas mothering is biological, nurturing, and caring in a more physical and emotional way, the father becomes the caregiver in a detached or distant way, by being a monetary support and an authority figure. Due to these preconceived expectations, the father is often not expected to be equally committed to the child, and is not punished for being aloof, distant or unavailable to the child. Brezis et al (2015) found that while narrating something about their children, fathers often spoke indirectly, derived a lot from their wives' experiences, spoke of their wives a lot, and were less likely than mothers to speak about their relationship with their child.

However, each of the fathers did have some way in which they contributed to the growth and the developmental of the child. Though these functions were not basic nurturing functions like feeding and bathing the child like the mother is expected to do, they did have an important role to play in how the child was raised. Anika and Nimisha talked at length about how their husbands were supportive of them and their efforts to take care of the children, and how the husbands overlooked minor 'transgressions' like an unclean house for 
the sake of their children. Nimisha also spoke of her husband being a passive outlet for her frustrations on certain occasions. Rohit also talked about how he was the more futureoriented parent, and how his way of supporting his son was by supporting his wife:

"I am not involved in (day-to-day) things because my wife will do the thinking for the particular moment or the particular day. So that thinking about the future I do take more actions. So I would say ki future vaali cheez pe (things) I focus more ki kaunsi cheez hai joh hum kya karein jisse voh khudse karna shuru karde (what should we do to make him more independent). Ki therapy kahan karani hai, kaunse doctor ko dikhana hai (Where should the therapy be done, which doctor should be consulted), stem cell therapy. In those things that my wife does, I am in support of her ki jahan pe voh thak jaati haiyaa exhaust ho jaati hai ki mujhse nhi ho paa rha hai, toh kyunki mein job pe hoon I have seen more things than her. (when she gets tired or exhausted and says that she can't do something, I take over. Since I have a job outside I have some more ideas that can be implemented.) I don’t support Laksh directly but I support my wife" (Rohit, personal communication, April 20, 2020).

Rakesh talked extensively about his decision to take a sabbatical from his job to spend more time with his son when he felt that some drastic step had to be taken to improve his relationship with his son:

"And that is when I took the decision and I quit my job, and my wife totally supported me. I will actually devote myself to whatever he needs to do. So if my son wants to play, I should be able to play with him. I should help him in understanding a few things, making him more active and doing all those things. I actually spent almost a year and $1 / 2$ with him on, I think, a lot of time playing with him, uh, exclusively playing with him. All of them (my family) actually realized after I started spending more time with Sarthak, he started 
showing a lot of positive development. Everyone across our lives started seeing that

Sarthak had started developing well” (Rakesh, personal communication, May 4, 2020).

It was evident from these narratives that there is a lot of love that these fathers had for their child, and their main motivation for doing anything was to improve the lives of their children. They tried to educate themselves to the best of their abilities, and in the case of Rakesh, even went against traditional parental roles. These narratives opened my eyes to the often overlooked experiences of these fathers in raising children with special needs, and their unending, pragmatic and optimistic devotion towards the betterment of their children.

The multiple roles of the father could be grounded in psychoanalytic theory and the understanding of the father as given by Sigmund Freud in his works from 1920s to the 1960s. Freud saw the father and child relationship as dynamic in nature and focussed on how the father needs to be strong and dependable for the healthy growth of the child. According to Stone (2008), Feudian theory recognizes the father as an early object of love and identification (1925), knowledge (1909/1955), a powerful godlike being who is omnipotent (1927), a protector (1930) and an authority figure with the metaphoric castrating authority (1911/1958). This array of roles that the father plays in the life of the child was evident even during the interviews.

The role of the father and its importance can be seen from the lens of the child in Tito Mukhopadhyay's writings, especially his book The Mind Tree. He wrote about how his father was not usually present, whereas his mother was, and that his father was the person who helped support the mother in supporting the Tito. He was often disappointed with the underwhelming reactions his father gave when he made an achievement (like uttering his first syllable), and spoke about him as an 'other', away from the mother-child dyad. Though he did not speak negatively about his father, the comparatively greater role of the mother in his life was evident. 
It was important to focus on both the mother and father's role in raising a child with autism, and shedding light onto their experiences. Research such as that of Brezis et al (2015), talk about how autism research and intervention is very child centric, and not enough attention is given to parental factors and their role as caregivers in the long and short-term development of the child.

\section{Child-Centric lifestyles adopted by the parents}

Through the interviews of the parents, it became abundantly clear that their lives, in some way or the other, were centred around their child. Though one can argue that every devoted, loving parent would centre their life around their child, I felt that these parents went above and beyond to ensure that their expectations from the child, and the special needs of the child were met in every way possible.

Every parent who was interviewed had extensively shifted their own schedules (and that of their husband or wife) to support the education, interventions, and physical and emotional needs of the child. Parvesh often took leaves from his job to take his son to the hospital, either to consult specialists or due to the many other health concerns his son showed. He did not want his wife to go alone for consultations as he wanted his son to get the best possible intervention that he could afford. Nimisha took diligent notes of the doctor's appointment and used to work with her son to bring him at par in developmental milestones, and refused to give up no matter how many doctors told her that it was not fruitful. Upon hearing that a particular hospital had good IQ testing, she went there with her son everyday for nine months, and waited for an appointment for 12 hours everyday, just to ensure the best interventions possible for her child. Anika, as a mother of two children with special needs, had to leave her law degree when her sister-in-law refused to take care of her daughter, gave 
her son speech therapy, occupational therapy and physical therapy all by herself, and later shifted around her entire schedule to devote herself to the children. She said:

"I have scheduled my entire day...used to get up at 5/5.30 am...used to cook everything before 7.30...then I used to wake the kids up, father used to bathe them, get them ready for school...when the kids were in the school, leftover work I used to do... Both the kids have studied from Marathi medium which is their mother tongue...I myself studied in English medium, for me Marathi was very difficult, I hardly used to pass also in school, so teaching them was a bit difficult. I used to bring all the books in English and Marathi. I used to read the English books first, then read the Marathi text, and then used to prepare lessons for the kids about what I have to work with them when they came home, or else the next day or something in the week or on the weekend. I used to plan weekends also beforehand. For example, the coming Saturday we are going to the garden, so what is a garden, what will do there, which clothes they will be wearing, with whom they will be going. These conversations used to start beforehand and would continue half of the next week also, I had planned this way. Then their vocab used to increase and some new things I used to explore with them, asking questions and then tell them. I did that continuously till date" (A, personal communication, May 2, 2020).

Saanvi, too, talked about her rigorous schedule after she started working as a single mother:

"Living at my maternal place so mom used to help out. Used to get up at 3:30 or so and used to complete all the household work, I used to get up early and travel with my child to my school, and she used to leave him in a classroom, but he did not sit at all, he used to roam around the whole school, somebody used to give me his pants, someone used to give me his shoes. Sometimes he used to go to the terrace and look at the children then some guard would see him. But guards are also at a different place, and why would anyone else 
take care of your child. It was difficult because I had to get that money, so I managed for three months. When there was assembly, he went into the music room, and I don't know what he did to some guitar and tablas but they weren't working anymore. Although the school did not ask me to pay off, I thought it was time for me to leave. There was a saturation point that I could not handle" (Saanvi, personal communication, April 27, 2020).

Rohit moved to a different city away from her wife and son so that they could afford to keep up the various therapies going. He talked about how he had to specifically explain the situation to his boss and cut down on his office hours, and that his and his wife's social life had reduced drastically. He also explained how he and his wife had to make drastic changes in their schedules to keep up with their son who was hyperactive:

"So by the time we knew that he is hyperactive, we realized thati there will be a lot of physical activity, so we both started running to increase stamina. So humnein schedule bana rakha tha (we have made a schedule) that my wife would wake up at 5 in the morning and go for a run. In the evening, when I would come, I would go running for 1 hour to make us physically equivalent, I would say energy uske barabar honi chahiye (should be equal to him)" (Rohit, personal communication, April 20, 2020).

When these motherland fathers talked about their schedules, and how hard they had to work to make sure that their child was getting the best of opportunities, and was learning at a pace at par with neurotypical children, did I truly feel the depth of their love and devotion. They were willing to go to great lengths to safeguard their child's present and future, and were uncompromising in their actions, whether it affected their personal or professional lives.

A similar experience was seen in the book The Mind Tree by Tito Mukhopadhyay, where he wrote about his childhood, and how his mother's life revolved around him. She used to 
take him to a therapist in a different city by the morning train, and return the next day. Eventually, she decided to move to that city with Tito, leaving her husband behind, just because that place had better schools catering to Tito's special needs. She had also changed her entire schedule and spent hours and hours everyday working with him, improving his writing skills, motor movement skills, and reducing 'challenging' behaviours. He wrote about how she never quit, and how her persistence towards his growth and development is what made him excel at writing at such a young age.

Another way in which it became clearer that the parents' lives revolved around their children was how inadvertently the interview shifted towards talking about the child. The parent's did not take as much time to answer questions about their childhood, education, marriage, etc., than they did talking about their children, even when the number of questions for both topics was the same. One such extract stood out from Nimisha's interview, where she had talked about her son, comparing him to Lord Krishna (a God in Hinduism):

"Bhagvaan ki daya hai; hum isko nhi dekhte hain toh hamari subah nhi hoti hai; hamari raat nhi hoti isko sulaaye bina. Aap bhagwaan ko maante ho? Krishna ko dekha hai. Mera Virat iss yug ka Krishna hai. Jaise Krishna bhagvaan ko harr koi pyaar karta than aa vaise hi hai voh. Uske mann mein kisi ke liye bhi kuch buran hi hai. Mujhe aajtak koi mila hi nhi hai jisko Virat nhi accha laga ho. (It is god's grace. It's not morning until we see him and not night until we make him sleep. Do you believe in God? Have you seen Krishna? My son Virat is the Krishna of this era. Just like everyone loved Krishna, everyone loves him. He doesn't have any negative feelings in his mind about anyone. I have never met anyone who hasn't loved Virat)" (Nimisha, personal communication, April $25,2020)$.

The centrism of her son in her life became clear after she said this. It was an emotional moment of the interview, where even I could feel the love she felt for her son. 
In a research article on the Indian perspective on ASD, Juneja and Sairam (2018) talk about how in Eastern cultures, family practices themselves are centred around the child, and parent-mediated interventions are not uncommon. However, such interventions and lifestyles may become ineffective when the majority of the load rests on the mother, along with the responsibility for household chores. The lack of family or social support would hinder their ability to take care of the child.

\section{Social Support and its importance (Emotional/Informational Support)}

One common theme that emerged in five out of the six parents who were interviewed was the importance of the presence of social support in their lives. Their support system provided them with backing in emotionally turbulent times, and even helped gain information and knowledge about autism. The two sub-themes under this umbrella are thus the presence of an Emotional Support System and the presence of an Informational Support System.

Emotional Support System. All the participants, at some time or another, had gone through emotionally challenging times with regard to their children. They had to face society's judgement, their personal guilt induced through that, and often their own family's rejection of their child. At these times, and many others, there was a need for consistent and non-judgemental support from people. Some participants spoke of receiving this support in times of need. Nimisha spoke of how major support came from her mother:

"Joh mujhe Virat ke maamle mein sabse zyada firm support mila voh meri mummy ka tha.

Pehle mummy se mila uske baad husband se mila. Even mere badhe bete se bhi mila.

Mummy ne mujhe bola ki koi baat nhi beta. Bhagvaan joh de voh prasad hota hai. Toh meine bola ki maa, yeh bacha theek nhi hoga matlab aise hi reh jayega. Toh phir kya karega. Maa ne bola ki bhagvaan ne harr insaan ko ahaar diya hai. Roti hi khayega naa. Jab tak hum hain, iske papa hain, nana nani hain, tab tak hum roti khilayenge. (The 
biggest support I got in Virat's situation was from my mother, my husband and my elder son. My mother said that it's ok. Whatever god gives us is a blessing. I asked her if my son would always remain like this. She said that god has given every person food. He will eat. Till the time he has a mother, father, and grandparents, we will feed him)" (Nimisha, personal communication, April 25, 2020).

Rakesh called his wife "a perfect ally" for him and commended his mother for choosing the "perfect partner". Saanvi expressed her gratitude for having such understanding parents who supported her emotionally as well as financially. Anika even talked about the doctors who reassured her that everything would become alright if she worked with her child diligently, and that she had nothing to worry about. Her friends, her husband's friends and even her son's friends have had a major role to play in the way she perceived her life. Though she had her own battle with depression and suicidal thoughts, her husband and children and their support was what kept her going. Nimisha even compared certain doctors to God, with how much they had helped her emotionally deal with her son's diagnosis of autism. Rohit shared his experience of feeling supported after his parents finally understood and accepted that his son had been diagnosed with autism.

"So jab unka support mila toh I was more ki chalo I am not alone. Ki abhi tak toh mein aur wife akele hi lage hue hain and aur ksii ko samajh hi nhi aa rha kuch bhi ki ho kya rha hai. Toh when they have started to support toh khud ko bhi energy milti hai, cheezein thodhi asaan ho gayi. Abhi voh log video call karte hain. Toh unko pta hai ki baat cheet karni hai Laksh se, poem gavani hai, toh video call ki through they kind of promote him. Laksh ko they will say ki yeh bolo, hi, bye, yeh sab. Support is very much regarding family and obviously wife ka toh hai hi support. (So when I got my parents' support, I thought that I am not alone. Till that time my wife and I were at it alone and nobody else could understand much. So when they started to support, we also got energized and things 
became easier. Now they video call and they know that they have to talk to Laksh, make him sing a poem, and through the video call they kind of promote him. They will tell him to say hello and bye. Support is through the family, and obviously through my wife.)" (Rohit, personal communication, April 20, 2020).

Given the physical, mental and emotional energy that goes into raising a child, it is important for the parents to have their own outlet for emotions, and a steadfast support system. These parents felt very strongly that their emotional support system had a very big role to play in their successful parenting.

Rakesh talked about support groups through organizations like Forum for Autism or whatsapp and Facebook support groups, and how they have evolved into helping younger parents feel emotionally supported. He said:

"I feel that these parents do require a lot of emotional support which they get by being a part of these networks where they can go out and share some of these experiences without having to censor some of these experiences. Sharing your experience freely would mean you would not expect to be criticized and the support groups I think until now has not had people who have bean critical. I think people have been very, very, very welcoming, and maybe somewhere I think the sense of solidarity is very clearly there is a sense that we are all in similar boats" (Rakesh, personal communication, May 4, 2020).

A major part of the support system, most clearly for Nimisha and Anika was that provided by religion and faith. It gave them backing, and their internal turmoil was often assuaged by the comforts of following a religion. Nimisha even felt that due to some offerings that her mother had made to a particular god, her son had started reaching his developmental milestones and his 'condition' had improved drastically. Other parents also spoke of how they could only wish to work hard and have faith that their child would have a good life. A study by Divan et al (2012), showed that seeking emotional support, empowerment (through 
education) and turning to religion and spiritual beliefs are certain ways parents cope with the challenges that they face when raising a child with autism. Shorey et al (2019) conducted a study which had similar findings about religion and faith as a coping strategy in the Asian context.

Information Support System. As was discussed in the previous themes, most parents had little to no knowledge and familiarity with autism, and were often lost when they heard this term. The presence of informational support systems in their lives drastically increased their knowledge and reassured their decision-making about their children. Saanvi talked about her introduction to autism through her school friend whose relative's son was also diagnosed with autism, and how without that, she would not have known to show her child to a specialist. Rakesh also spoke of a known person who became his informational point of contact:

"We also got to know some acquaintances in my wife's family who also happen to be in the area of special education so gradually getting to know that was positive. She became our go-to person, and being a part of the extended family we were quite comfortable sharing our concerns with her and Sarthak was also comfortable in her presence. She started giving us which exercises which Sarthak could do" (Rakesh, personal communication, May 4, 2020).

He also spoke of support groups through organizations like Forum for Autism, as well as Facebook support groups. He said that their importance boiled down to a platform for “sharing experiences, challenges, and what works or doesn't work with other parents and help in guiding others as well". They helped him form a network of friends, who provided him with knowledge, information and often opportunities for his son. He also spoke about using these informational resources to get educated about autism, as he did a specific course on autism and its manifestations in children. Anika also mentioned that through the support 
and information provided by her daughter's school, she pursued a training programme which taught her to do occupational therapy and speech therapy, and attended various workshops through organizations like Action for Autism. These were especially essential for her since at that time, due to no internet, these workshops became the major source of knowledge available to her.

Nimisha, Anika and Rakesh even talked about how they had become informational and even emotional support for other parents whose children were diagnosed with autism. They often helped them with resources, knowledge, and even helped explain concepts to them that the doctors made out to be too complicated. This helped the participants by giving them an added sense of purpose, and validated their own feelings and concerns.

Thus, the support system, manifesting in different ways, whether through family, friends, peers, doctors, children or even religion, played a major role in the lives of the participants, and helped them become aware and get educated about autism, as well as helped them manage their emotional responses around it. This theme can be viewed in light of the Family Systems Theory, originally given by Bertalanffy (1976), who viewed the family unit as comprising of systems, all of which had their own part to play. For instance, in a family, the multiple systems that exist could be the mother-father unit, mother-child unit, father-child unit, sibling unit, etc., each having a unique contribution to how the family functions. In light of a family with a child with autism, the different units of the family would comprise of the social support that the child or the parent has. The grandparent unit, especially in India, holds special significance in terms of accepting or not accepting the child and his diagnosis of autism, thereby reducing or increasing the stress of social stigma for the parents. The sibling unit can also be added support for the parents, by being extra help in managing the child with autism, helping out in other duties like household chores, and also embodying the typical aspirations that the parents may have from the child, thereby not putting too much pressure 
on the autistic child. Peers and friends can also be thus seen as extensions of the family system, contributing to the social support in their own ways.

Gobrial (2019) found that social support was an important part of the narratives of mothers, and that they educated and empowered themselves in the field of autism to cope with the diagnosis in a better way. In a study, Willis (2014) found that shared support was an important resource to have to adapt to the needs and demands of raising a child with autism. In their study, Altiere and von Kluge (2009) also found that there was a major loss of social support in the lives of the parents after the diagnosis of their child, but there was also growth in what they called 'true friendships'. There was also a lot of solution-orientated approach adopted by the parents, including educating and empowering themselves. The findings of these studies were also validated by the findings of the present study.

\section{Socioeconomic and Cultural Positioning affecting their understanding, response and}

\section{coping of their child's autism}

The last theme that was implicitly observed through the narratives was how the socioeconomic and cultural positioning of each of the parents affected the way in which they understood autism, responded to the diagnosis, and coped with the challenges of raising a child with autism. As the present study tried to contextualize the different narratives, it also shed light on why the parents had such diverse experiences. No two participants had the exact same knowledge base, emotional response or social support system, owing to the variations in their backgrounds.

Certain aspects and extracts from the interviews have been analysed to understand their relation with the positioning of the participants. A major point of difference was the accessibility or inaccessibility to the Internet and its influence on the understanding of autism that the parents held. Anika, whose son was diagnosed over 20 years ago, spoke of how due 
to the lack of resources like the internet, she was not able to gather much information about autism initially. Parvesh, who belonged to a relatively lower income family, and who had limited access to the internet, could not use it to understand the term autism, and was still unaware about its meaning during the interview, even though his son had been diagnosed a few years ago. On the other hand, Saanvi, Rohit and Rakesh had ample access to the internet, and kept evolving their understanding of autism and their children.

The second major point of difference was the accessibility to services like clinics, psychologists, therapy and intervention centres partaking in occupational therapy, speech therapy and special education, etc. Studies by Divan et al (2012) and Desai et al (2012) found that access to services like clinics and therapy centres, financial burdens and constraints and societal attitudes towards disability can cause elevated levels of stress in the parents and can affect their coping mechanisms. In the present study, the accessibility to these resources were dependent either on family income and affordability, or on the geographical location of the participant. Parents who had higher paying jobs and resided in metropolitan cities in India, like Rakesh, Rohit and Anika, had greater access to these services. They could afford to send their children to schools catering to the needs of special children, take up courses and workshops to educate themselves, and afford to consult specialists like developmental psychologists. However, participants with lower-incomes, like Nimisha and Parvesh, and those living in small towns, like Saanvi, were often forced to make do with whatever scarce services were available. Nimisha talked extensively about the abysmal state of government hospitals catering to the needs of children with autism, and her struggle to get decent care and interventions for her son. Saanvi also spoke of her efforts at home therapy and interventions for her son, and her struggles with travelling to far off places just to consult a psychologist. Brezis et al (2015) talk about how professional services in small towns and cities in India can be so scarce that parents and caregivers have to take it upon themselves to educate 
themselves and provide therapeutic interventions to their child. Parvesh and his wife were worried about the most basic academic growth of their son, to whom the teachers in government schools did not pay any attention.

Even though these differences were implicit, they were stark in nature, and were an important part of how the interviews were conducted. There were subtle differences between the flow of the interviews of english-speaking participants and hindi-speaking participants. Brezis et al (2015) found that English-speaking, urban and higher income parents were more likely to reflect on their parenting, talk about society and community and to see the child as their 'teacher'. They called this a 'cognitive luxury' that could be afforded due to their socioeconomic status. On the other hand, relatively lower income, Hindi-speaking parents were more likely to focus on the child's independent skills, speak about concerns regarding their child's life after their death, and talk about religion or faith. These findings also hold true for the present study.

\section{A Reflective Account of the Interview Experience}

As a first time interviewer for such a study, the process of interviewing was a gradual learning experience with which I became more comfortable over time. While preparing the interview questions, I was quite clear about the themes that needed to be focussed on, but I was not prepared for the parents diverting all the time to talking about their child more than themselves. During the first interview, owing to the short and curt responses, I could not probe deeper into the personal life of the participant, as they focussed on talking about their child. As the interview went on, rapport was built and I was more comfortable in asking counter-questions taking into account the meanings behind the participant's responses. However, the chance to gather some meaningful data during the first half might have been lost. From the next time onwards, it became easier for me to ask participants to elaborate on 
their answers, and probe more into vague responses. I feel that my interview skills were honed, and I was able to make most of my participants feel comfortable answering my questions. Since the interviews were carried out over phone calls, it was also difficult to see the non-verbal responses that the participants gave, and everything had to be taken on face value. There was no possibility of understanding aspects of their body language, including posture, intonation, silences, expressions, etc., which are important to fully analyse any interview.

Reflecting upon the process, I also realized that the perceived socioeconomic status of the participant had an effect on my own ability to relate and comfort level during the interview. For instance, I felt a lot more at ease interviewing the participant who spoke fluent English, belonged to a metropolitan city and had a basic background of psychology. This participant was also the one who spoke for the longest time and the only participant who devoted equal time to talking about themselves and about their child. I believe that through unconscious processes of transference and countertransference, there was a mutual rapport that was built, making each of us comfortable with each other. On the contrary, I felt uncomfortable at the prospect of interviewing a participant who had a colloquial accent, spoke in Hindi, came from a lower socioeconomic background, and did not even recognize the word 'autism' when I first sought him out for the interview. I was unsure of my abilities of relating with him and his experiences, thereby curbing my ability to probe and question deeply. I was also well aware of the power dynamics between us, especially as he referred to me as "ma'am" throughout the interview, even after I insisted that he call me by my name. He may have unconsciously been aware of my discomfort (through countertransference) and it may have hindered rapport formation, leading to only surface-level answers by the participant.

Power dynamics in the interview process were present both implicitly as well as explicitly. Participants often called me "ma'am" (while I also addressed them as "sir' or "ma'am" to 
balance the power) and even asked me technical questions about autism, believing me to be a clinical practitioner who could make their child "better". I took an opportunity towards the beginning and the end of the interview to clarify that I was a masters student with no authority or training to answer these questions. Another aspect of the interviews that might have shifted power to me was the assumption of the participants about my age. Though I did not have the foresight to mention my age in the introduction, some participants assumed that I was above 30 years, and with that came a certain experience authority attached to it. Two of the participants were shocked to learn that I was much younger, when they enquired about it during the closing of the interview. Looking back, it was my hope that those participants did not lose confidence in my abilities, or feel that I was duplicitous.

I believe that my own feelings and emotions had a huge role to play in the way that I perceived the interviews as well as my writing of the paper. Due to my own difficult relations with my family, and my perception that my mother has sacrificed a lot in life for me and my sibling, my understanding of caregiving relations are inclined towards a soft side for the mother. During the interviews, I was in awe of what these mothers had given up for their child, and how they continued to juggle multiple roles in their lives which struggling against the social stigma surrounding autism. I got emotional during multiple instances while interviewing the mothers, which might also have led to the mothers believing that I relate to them, thereby building rapport. I have also painted a relatively positive picture of motherhood while discussing the themes, emanating from my own experiences and perceptions. The lockdown and the pandemic situation also might have made me hold back on asking deeply personal questions, as I did not wish to be insensitive and invade their personal space during these challenging times.

Reflecting back on the interviews, I was also made aware of how my presence itself would change the way parents would express their emotions and experiences. Three of the 
participants had previously been interviewed by other researchers on similar topics, and it might be possible that they had a set of answers ready, depending on what they wanted to share. Even though the questions were not shared beforehand, I can assume that previous researchers would at least have some overlapping interest areas and questions. This might have led to pre-decided answers, and may not be representative of the full picture of the experience of the parents. On the other hand, however, it may also indicate that the participants were comfortable with answering questions and were open to sharing their narratives as they had done so previously.

It was also observed that all the parents painted a very positive and rosy picture of their child, and spoke of any behavioural challenges as mere nuisances, which they were equipped to deal with. It is a definite possibility that the parents refrained (consciously or unconsciously) from saying anything negative about their child from the fear of being judged or seen as 'bad parents', or they may not have conscious access to certain unconscious emotions that they might have been feeling. Parenting as an experience can be joyful, challenging and even ambivalent at times. However, during the interviews, the joyful experience was at the forefront, the challenging experience was stated explicitly, but the ambivalent nature of parenting did not come up. A truly authentic narrative might not have been obtained in this case.

Lastly, the coronavirus pandemic and nationwide lockdown may have resulted in a temporary change in the parents' narratives and emotions. Caring for the child 24/7 may have increased the frustration in the parents, especially mothers, who may have to bear the burden of housework as well. On the contrary, the pandemic and the anxieties surround that might have increased the protectiveness of the parents towards the child, and the increased time spent with the child (especially by working fathers) may have altered the responses they gave 
during the interviews. The responses, analysis and results of the research should be understood keeping these aspects of the interview process in mind. 


\section{Conclusion}

The present study was aimed at understanding how parents of children with autism understood autism, their emotional responses to autism, and how they coped with the unique challenges in their lives. It was based on a personal motivation of wanting to include the narratives of parents in the understanding of the growth and development of the child.

A theoretical background of the Family Systems Theory (Bertalanaffy, 1976), which focussed on how each member of the family has a unique contribution to make to the whole, was adopted. The Indian setting, where the collectivistic nature of society makes the family a centre part of the child's life, was also kept in mind. Due to the need for severe care required by children with autism, their primary caregivers were seen as the most important figures in playing a role in the child's upbringing and the prognosis of autism.

According to the approach of the study, the research fell into the Subjective Constructivist paradigm, which emphasized that the researcher is a filter for the information provided by the participant, and influences how the information is perceived and reported. It also followed the Psychosocial understanding of autism, and looked at each narrative as rooted in a particular sociocultural and economic context. Participants were sought out through Facebook support groups and organizations like Forum for Autism. Six participants ( 3 mothers and 3 fathers) were interviewed over phone calls, and spoken to on areas like their upbringing and childhood experiences, life in the marital dyad, relation with their child, emotional responses to the diagnosis of autism, social and familial support, hopes for the future and the effects of the coronavirus in their lives.

The Narrative Thematic Analysis method (Reissman, 2005) was used to derive themes based on anecdotes and vignettes from the interviews, perceptions about the narration, and were understood in light of the contextual positioning of each participant. The first theme that emerged was the 'lack of knowledge about autism in the parents', and it was observed that 
most parents had no familiarity with this term before their child was diagnosed. Overtime, the understanding shifted from autism meaning something was 'wrong' with their child, to accepting that their child just had a different experience of living. The second theme that was discussed was 'the emotional upheaval of parents over time'. Parents used words like "shocked", "devastated", "angry" to describe their initial feelings, but gradually moved to more problem-focussed approaches, engaging with doctors and planning interventions for the child. Most of the parents eventually reached absolute acceptance of the child, with great hopes for their child's future. When speaking of parents, the role of mothers and fathers was analysed separately. It was seen that mothers showed absolute devotion to the child and its needs, and were physically, mentally and emotionally burdened with caregiving, juggling the role of mothers, wives, daughters, professionals, and even co-therapists. The role of the fathers, though outwardly limited to financially supporting the family and acting as a disciplinarian, it extended to also being more future-oriented and supporting the mothers. The next theme that was discussed was the 'child-centric lifestyles adopted by the parents', where they went above and beyond to ensure the best for their child. The parents had to often extensively shift their schedules to accommodate the needs of the child, move to different cities for better opportunities for care, and had to often compromise on their professional and social lives. This was made possible largely due to the presence of 'social support and its importance', which was the next theme that was discussed. The participants derived support from their spouses, families, friends, support groups, and even through religion. The presence of emotional validation as well as information about autism made their journeys much easier. The last theme which emerged implicitly was the 'socioeconomic and cultural positioning affecting their understanding, response and coping of their child's autism'. It was seen that the a higher family income and residence in a metropolitan city increased the access to internet and resources like clinics and psychologists, thereby improving their understanding 
of autism and ways of coping to challenges.in their lives. Reflexivity in the research was discussed and personal biases that may have entered were also put forward for the readers discretion. The impact of the presence of the interviewer, especially in the coronavirus pandemic was delineated.

The study was done in light of the major role that parents play as caregivers in the upbringing of a child with autism, and it hold certain implications and suggestions. Psychologists and therapists working with children should take into account the experiences of the parents while designing any interventions for the child. These experiences also teach us that the social stigma that surrounds autism needs to be systematically changed, and autism should be seen as a different life experience of the child than something 'wrong'. The parents also urged for better services and representation of their children in India, and said that is the key to reducing this stigma. Additionally, support through counselling or training should be provided to the parents as they take on the challenges of raising a child with autism, and can even be ostracized due to the social stigma surrounding autism.

However, there were certain limitations in the study. The number of participants interviewed were low, thereby reducing the generalizability of the results of the research. Due to the nationwide lockdown due to Covid-19 pandemic, the participants were interviewed over phone calls. Thus, their body language, including posture, intonation, gestures, etc., could not be seen, leaving out a major part of findings from the study. The added anxieties around the pandemic might have also affected their emotions and their answers. Interviews with the spouses of the participants to gain even greater understanding into the family dynamics, were also not possible due to their unavailability during the lockdown. Due to lack of proper rapport formation, truly authentic interview answers might not have come across, and parents may have wanted to portray a positive picture of their lives so as to not be judged. 
Future research can take on bigger sample sizes, coming from diverse backgrounds.

Holistic research with multiple stakeholders including parents, siblings, grandparents, friends, and clinicians, along with the child, can also be undertaken for better understanding of the subject. 


\section{References}

A. (2018, March 2). Severity Levels in the DSM-5's New Autism Spectrum Disorder: Requiring Support, Substantial Support and Very Substantial. Autism Spectrum Disorder. https://www.opposingviews.com/health/severity-levels-in-the-dsm-5-s-new-autism-spectrumdisorder-requiring-support-substantial-support-and-very-substantial

Altiere, M. J., \& von Kluge, S. (2009). Searching for acceptance: Challenges encountered while raising a child with autism. Journal of Intellectual \& Developmental Disability, 34(2), 142-152. https://doi.org/10.1080/13668250902845202

American Psychological Association. (2013, February). DSM-5 Autism Spectrum Disorder. https://depts.washington.edu/dbpeds/Screening\%20Tools/DSM5\%28ASD.Guidelines\%29Feb2013.pdf

Autism Diagnosis Criteria: DSM-5. (n.d.). Autism Speaks. https://www.autismspeaks.org/autism-diagnosis-criteria-dsm-5

Baker, J. P. (2013). Autism at 70 - Redrawing the Boundaries. New England Journal of Medicine, 369(12), 1089-1091. https://doi.org/10.1056/nejmp1306380

Bluth, K., Roberson, P. N. E., Billen, R. M., \& Sams, J. M. (2013). A Stress Model for Couples Parenting Children With Autism Spectrum Disorders and the Introduction of a Mindfulness Intervention. Journal of Family Theory \& Review, 5(3), 194-213. https://doi.org/10.1111/jftr.12015

Brezis, R. S., Weisner, T. S., Daley, T. C., Singhal, N., Barua, M., \& Chollera, S. P. (2015). Parenting a Child with Autism in India: Narratives Before and After a Parent-Child Intervention Program. Culture, Medicine, and Psychiatry, 39(2), 277-298.

https://doi.org/10.1007/s11013-015-9434-y 
Chadda, R., \& Deb, K. (2013). Indian family systems, collectivistic society and psychotherapy. Indian Journal of Psychiatry, 55(6), 299. https://doi.org/10.4103/00195545.105555

Chakravarti, U. (2008). Burden of Caring. Indian Journal of Gender Studies, 15(2), 341363. https://doi.org/10.1177/097152150801500207

Chang, L.Y. (2009). Medicine and Society: An Investigation on Medical Sociology, 4th Edition. Taipei: Chuliu. (in Chinese).

Crowell, J. A., Keluskar, J., \& Gorecki, A. (2019). Parenting behavior and the development of children with autism spectrum disorder. Comprehensive Psychiatry, 90, 2129. https://doi.org/10.1016/j.comppsych.2018.11.007

Dauman, N., Haza, M., \& Erlandsson, S. (2019). Liberating parents from guilt: a grounded theory study of parents' internet communities for the recognition of ADHD. International Journal of Qualitative Studies on Health and Well-Being, 14(1), 1564520. https://doi.org/10.1080/17482631.2018.1564520

Desai, M. U., Divan, G., Wertz, F. J., \& Patel, V. (2012). The discovery of autism: Indian parents' experiences of caring for their child with an autism spectrum disorder. Transcultural Psychiatry, 49(3-4), 613-637. https://doi.org/10.1177/1363461512447139

Divan G, Vajaratkar V, Desai MU, Strik-Lievers L, Patel V. Challenges, coping strategies, and unmet needs of families with a child with autism spectrum disorder in Goa, India. Autism Res. 2012; 5: 190-200.

Fletcher, P. C., Markoulakis R., \& Bryden, P. J. (2012). The Costs of Caring for a Child with an Autism Spectrum Disorder, Issues in Comprehensive Pediatric Nursing, Vol. 35 (1), pp. $45-69$. 
Feinstein, A. (2010). A History of Autism: Conversations with the Pioneers. UK: John Wiley \& Sons.

Gobrial, E. (2018). The Lived Experiences of Mothers of Children with the Autism Spectrum Disorders in Egypt. Social Sciences, 7(8), 133.

https://doi.org/10.3390/socsci7080133

Gray, D. E. (1994). Coping with Autism: Stresses and Strategies. Sociology of Health \& Illness, Vol. 16 (3), pp. 275-300.

Gray, D. E. (2002). "Everybody Just Freezes. Everybody is Just Embarrassed”: Felt and Enacted Stigma among Parents of Children with High Functioning Autism. Sociology of Health \& Illness, Vol. 24 (6), pp. 734-749.

Gray, D. E. (2003). Gender and Coping: the Parents of Children with High Functioning Autism. Social Science \& Medicine, Vol. 56, pp. 631-642.

Guba, E. (1990). The Alternative Paradigm Dialog. In The Paradigm Dialog (1st ed., pp. 17-27). SAGE Publications, Inc.

Happé, F., Ronald, A., \& Plomin, R. (2006). Time to give up on a single explanation for autism. Nature Neuroscience, 9(10), 1218-1220. https://doi.org/10.1038/nn1770

Hydén, L. C. (1997). Illness and Narrative, Sociology of Health \& Illness, Vol. 19 (1), pp. 48-69.

Jain R, Juneja M, Sairam S. Children with developmental disabilities in India: age of initial concern and referral for rehabilitation services, and reasons for delay in referral. $J$ Child Neurol. 2013; 28: 455-460.

Juneja, M., \& Sairam, S. (2018). Autism Spectrum Disorder - An Indian Perspective. SMG Group, 1. http://www.smgebooks.com/autism/chapters/AUT-18-12.pdf 
Kanner L (1943). "Autistic disturbances of affective contact". Nerv Child. 2: 217-250. $\underline{\text { PMID }}$ 4880460. Reprinted in Kanner L (1968). "Autistic disturbances of affective contact". Acta Paedopsychiatr 35 (4): 100-136.

Kenny, D. T. (2019). Faulty Theory, Failed Therapy: Frances Tustin, Infant and Child Psychoanalysis, and the Treatment of Autism Spectrum Disorders. SAGE Open, 9(1), 215824401983268. https://doi.org/10.1177/2158244019832686

Kuhn, R., \& Cahn, C. H. (2004). Eugen Bleuler's Concepts of Psychopathology. History of Psychiatry, 15(3), 361-366. https://doi.org/10.1177/0957154x04044603

Levine, N. (2017, September 5). Etymology of the Word “Autism” JewishBoston. https://www.jewishboston.com/etymology-of-the-word-autism/

Lu, Y. T. Suffering and Love between Genders: A Narrative Analysis of Autistic Children's Parents.

Loukisas, T. D., \& Papoudi, D. (2016). Mothers' Experiences of Children in the Autistic Spectrum in Greece: Narratives of Development, Education and Disability Across their Blogs. International Journal of Disability, Development and Education, 63(1), 64-78. https://doi.org/10.1080/1034912x.2015.1111304

Paiva, N. D. (2016). Keeping fathers in mind. Journal of Child Psychotherapy, 42(2), 122-134. https://doi.org/10.1080/0075417x.2016.1191199

Rehabilitation Council of India. (2003). Autism. http://www.rehabcouncil.nic.in/writereaddata/autism.pdf

Riessman, Catherine Kohler (2005) Narrative Analysis. In: Narrative, Memory \& Everyday Life. University of Huddersfield, Huddersfield, pp. 17.

Rolland, J. S., \& Walsh, F. (2006). Facilitating family resilience with childhood illness and disability. Current Opinion in Pediatrics, 18(5), 527-538. https://doi.org/10.1097/01.mop.0000245354.83454.68 
Ronald, A. Problem children problem parents. Indian J Pediatr. 1944; 11: 20-29.

Daley TC. From symptom recognition to diagnosis: children with autism in urban India. SocSci Med. 2004; 58: 1323-1335.

Roper, S. O., Allred, D. W., Mandleco, B., Freeborn, D., \& Dyches, T. (2014). Caregiver burden and sibling relationships in families raising children with disabilities and typically developing children. Families, Systems, \& Health, 32(2), 241-246. https://doi.org/10.1037/fsh0000047

Samms-Vaughan, M.E. (2014). The status of early identification and early intervention in autism spectrum disorders in lower- and middle-income countries. Int J Speech Lang Pathol 16:30-35.

Shorey, S., Ng, E. D., Haugan, G., \& Law, E. (2019). The parenting experiences and needs of Asian primary caregivers of children with autism: A meta-synthesis. Autism, 24(3), 591604. https://doi.org/10.1177/1362361319886513

Singh, M., Chauhan, A., Sahu, J., Jaiswal, N., Kumar, K., Agarwal, A., Kaur, J., \& Singh, S. (2019). Prevalence of autism spectrum disorder in Indian children: A systematic review and meta-analysis. Neurology India, 67(1), 100. https://doi.org/10.4103/0028-3886.253970

Stone, D.K. (2008). The forgotten parent: The father's contribution to the infant's development during the pre-Oedipal years. Aukland University of Technology.

Trzebiński, J., Wołowicz-Ruszkowska, A., \& Wójcik, A. D. (2016). The Impact of SelfNarratives of Motherhood for Mothers of Children with Autism. Frontiers in Psychology, 7, 1. https://doi.org/10.3389/fpsyg.2016.01899

Vaidya, S. (2016). Autism and the Family in Urban India. Springer India, 1. https://doi.org/10.1007/978-81-322-3607-8

Willis, M. (2014). Minority Parents' Narratives of Living with Their Child with an Autism Spectrum Disorder. Loma Linda University Electronic Theses, Dissertations \& Projects. 290. 
Woodgate, R. L., Ateah, C., \& Secco, L. (2008). Living in a World of Our Own: The Experience of Parents Who Have a Child with Autism. Qualitative Health Research, Vol. 18 (8), pp. 1075-1083.

World Health Organization. (2004). The importance of caregiver-child interactions for the survival and healthy development of young children. Child and Adolescent Health and Development, 1. https://www.who.int/maternal_child_adolescent/documents/924159134X/en/ 


\section{Appendix A}

\section{Informed Consent Form for Participants}

This informed consent form is for the parents who are invited to participate in the research titled "Narratives of Parents who have Children with Autism".

I am Yashaswini Gupta, a second year MA Psychology student in Ambedkar University Delhi. For my Masters Dissertation, I am working to study Narratives of Parents who have children with Autism. Below is some information provided about the research which would help you decide if you want to be a part of it.

My focus lies on the narratives of the primary caregivers of the child, and about giving them a voice. Autism requires for the child to be in constant care of the parents, and the fact that the child is always surrounded by them, their experiences should be given importance as well. The experiences of the parents vis a vis the child as well as with their environment become important in this context, and it becomes equally important to analyse any patterns in experiences or feeling across a range of parents of children with autism, in order to understand their effect on the child.

The research will include taking your interviews at a time of your convenience. The interviews would be 30-40min in duration, and approximately 1-2 interviews would be taken. If applicable and consented, interviews would also be conducted with your spouse/partner. The questions in the interviews would be related to your personal and professional life, your child and the relationship your share with the child. The interviews would be audiotaped for better understanding at later stages of the research process. The audiotapes would remain strictly confidential and would not be heard by anybody but the researcher.

After the interviews, a detailed transcript of your interviews would be shown to you, and you would have the liberty to discuss and retract any statement or part of that data. I would 
also invite you to write or talk about your interview experience, and any other topic which you feel would contribute to the research.

I reiterate that your participation in this research is entirely voluntary. It is your choice whether to participate or not. You may change your mind later and stop participating even if you agreed earlier.

If you have any questions, you can ask them now or later. If you wish to ask questions later, you may contact the undersigned at any time.

Yashaswini Gupta

(yashaswini.gupta1109@gmail.com)

\section{Consent Form}

\section{Statement by the participant:}

I have read the foregoing information, or it has been read to me. I have had the opportunity to ask questions about it and any questions I have been asked have been answered to my satisfaction. I consent voluntarily to be a participant in this study

Name of Participant

Signature of Participant

Date (Day/month/year)

\section{Statement by the researcher/person taking consent}

I have accurately read out the information sheet to the potential participant, and to the best of my ability made sure that the participant understands that the following will be done: 
1. Interview with participant.

2. Audiotaping of the interview

3. Sharing of interview transcripts

I confirm that the participant was given an opportunity to ask questions about the study, and all the questions asked by the participant have been answered correctly and to the best of my ability. I confirm that the individual has not been coerced into giving consent, and the consent has been given freely and voluntarily.

A copy of this ICF has been provided to the participant.

Name of Researcher/person taking the consent

Signature of Researcher /person taking the consent

Date (Day/month/year) 


\section{Appendix B}

\section{Pre-Interview Questionnaire}

Instructions: Please fill in the following questions to the best of your ability. This information would be kept fully confidential, and there will be no use of this information outside the purpose of the research.

Name:

Age:

Gender:

Educational Qualification:

Occupation:

Language preferred (English/Hindi/Both):

Name, age and occupation of partner/spouse:

Composition of Family (Parents/ Parents in Law/Children/Siblings etc.) in Residence:

Name of Child (optional):

Age of child:

Gender of child:

Is there any formal diagnosis of the child? If yes, please mention, and write any special needs the child has:

Is the child involved in any therapy, or work with any specialist?: 
What are the major developmental delays/ atypicality/ complaints or concerns about your child?:

What are some of the most enjoyable and pleasant moments with your child?: 